\title{
ON THE PROGRESS AND DEVELOPMENT OF THE MARINE ENGINE.
}

Br Mr. F. C. MaRshalL, of Newoastle-on-Tyne.

At the Liverpool Meeting in 1872, Mr. F. J. Bramwell, F.R.S., now Sir Frederick Bramwell, Past-President, read a paper before this Institution on "The Progress effected in Economy of Fuel in Steam Navigation, considered in relation to compound-cylinder engines, and high-pressure steam." This paper was most exhaustive in its character, and was followed by a discussion, in which some of our most prominent engineers took part.

Having been asked to prepare a paper for this meeting on the marine engine, the writer naturally turned to what had been laid before the Institution on previous occasions. He found that Sir Frederick Bramwell's paper embraced all the past history and present condition of marine engineering, and to some extent forecast its future. On the same occasion Dr. Siemens, F.R.S., the President for the year, remarked that during the nine years which had elapsed since the first meeting in that city the marine engine had been so far improved, that it consumed rather less than one half the amount of fuel at that former time thought to be indispensable; and that, if nine years later his successor were able to announce a similar step in advance, we should have the satisfaction of knowing that the further discussion of the subject that day had not resulted in "lost energy."

We have now completed the term then defined by Dr. Siemens; and the writer proposes to continue the subject from the date of that meeting, and endeavour to trace out whether any, and if so what progress has been made; further, to consider whether or no we have reached the finality so strongly deprecated by Sir Frederick 
Bramwell in the discussion referred to, and if not, then in what direction we are to look for further development.

In his paper Sir Frederick Bramwell gives Tables of particulars of the engines and boilers belonging to twenty-eight steamers of different deseriptions, and comprising nearly all the types of engine and boiler now in general use. These Tables embrace the sizes of cylinders, heating and grate surface of boilers, condensing surface, working pressure, speed of piston, indicated power, and consumption of fuel.

The average consumption of nineteen of these vessels he shows to be 2.11 lbs. of coal per I.H.P. per hour. The working pressures range from $45 \mathrm{lbs}$. to $65 \mathrm{lbs}$. per square inch, the latter being the highest pressure recorded, while 376 feet per minute is the average piston speed.

The writer has been favoured with data, from thoroughly reliable sources, showing in a similar manner the general proportions of engines and boilers recently fitted to steamers in the mercantile marine. These are shown in Table I. annexed (p. 452). It will be noted that the steam pressures are now much higher, the boilers have less heating surface, and the cylinders are much smaller for the I.H.P. developed; and at the same time the average consumption of fuel is reduced from $2.11 \mathrm{lbs}$. to $1.828 \mathrm{lbs}$, or by 13.37 per cent.

A substantial progress is thus shown to havo been made during the nine years; and although it does not reach the enormous gain of the previous decade, it is probably as much as could reasonably be expected, since the closer we approach the limit the more difficult will improvement become.

The Marine Engine of to-day is substantially the same in design and arrangement as Sir Frederick Bramwell described it. The compound two-cylinder vertical engine, with receiver, and with two cranks at right angles, as shown in Figs. 1 to 3 , Plates 53 and 54, is the most commonly accepted type. It embodies great simplicity in design, great facility -and therefore cheapness-in manufacture ; it has few moving parts, is easily handled and tended, is very accessible throughout the working parts while in motion, and is readily repaired. 


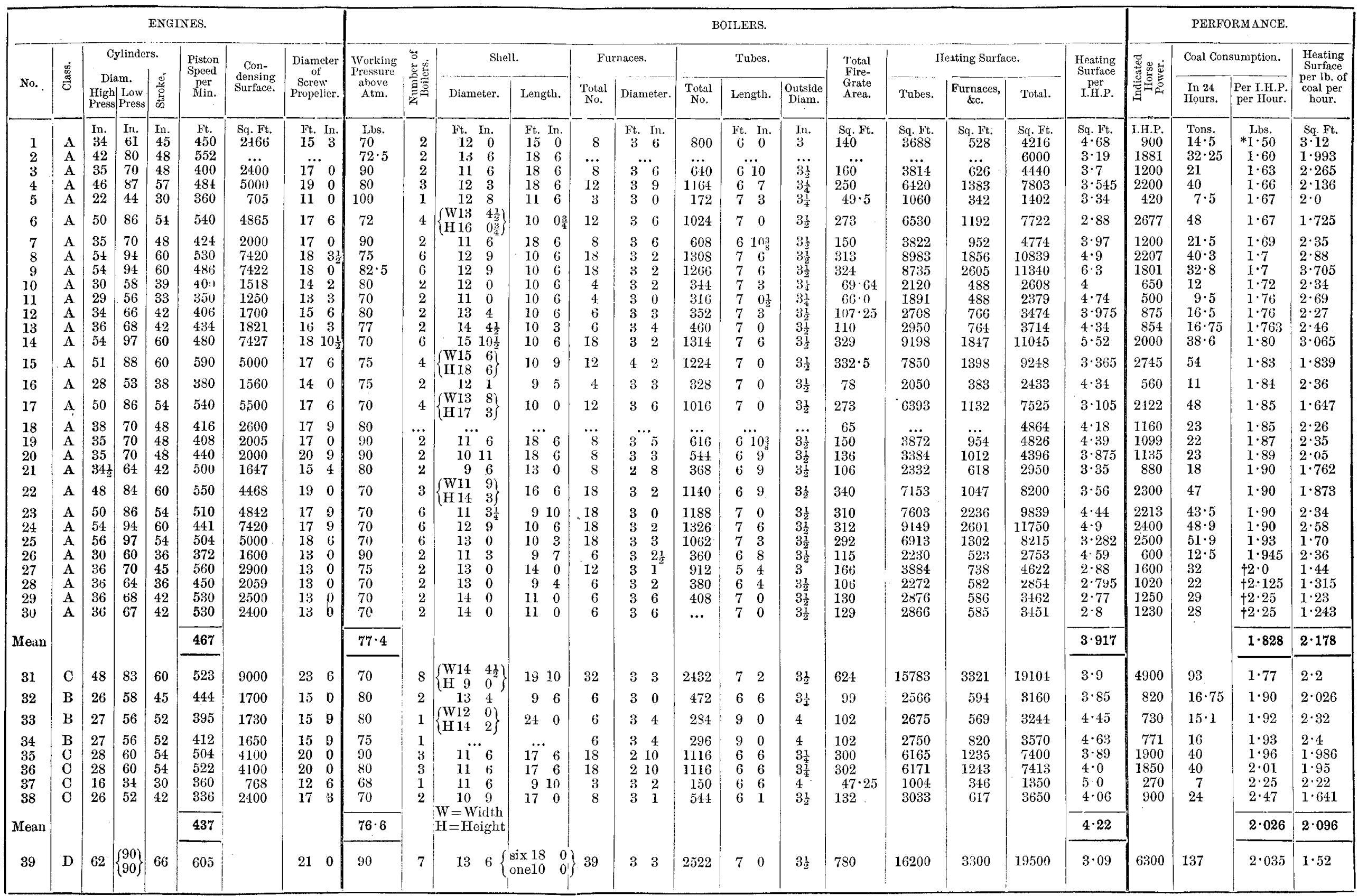

Class A-Compound Fugrines with one High and onc Low-pressure vertical Cylinder, working two cranks at right angles.
B one crank. Cylinders in line (tandem).

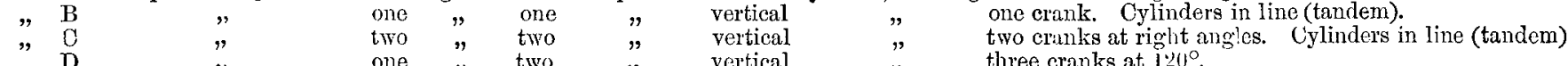

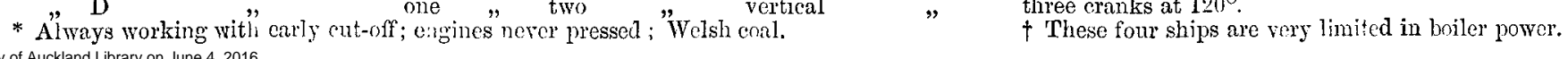


The single Woolf engine, commonly known as the Tandem Engine, with single crank and fly-wheel, as shown in Figs. 4 to 6 , Plates 55 to 57, was originally introduced and developed by Mr. Alfred Holt, and has recently been adopted by some other shipowners, with great satisfaction to themselves. It is still however looked upon with doubt and suspicion as to "unhandiness" by shipowners and their engineers generally, and therefore does not make much progress in numbers as compared with engines having cylinders side by side; and this notwithstanding the undoubted advantage it possesses, of taking up less fore-and-aft space in the vessel, and of having fewer working parts to be looked after.

Next in order of general acceptance to the two-cylinder receiver engine, with cranks at right angles, is that known as the Double Tandem Engine; which consists of two Woolf engines placed side by side, and working two cranks at right angles, Fig. 7, Plate 58. These engines have been extensively adopted for the largest transatlantic steamers, and with great success.

The tandem form of compound engine possesses the great advantage of independence of action, and may therefore be multiplied indefinitely in its application to one propeller. It has long been used in the double form, and last year at Barrow it was introduced to the notice of the Institution in its triple form, as applied to the City of Rome (Proceedings 1880, p. 340). So long as it is thought wise to concentrate the propelling power of a vessel in a single instrument, the number of such engines working side by side may be increased indefinitely. The triple or quadruple arrangement of such engines, as will readily be seen, gives great uniformity of strain, and greatly relieves the weight and friction on the crank-shaft, besides balancing all the moring weights. To set against these facts, there is of course the great disadvantage of increased number of parts, always a serious consideration on board ship at sea.

A modification of the Woolf engine, introduced by Mr. D. Rowan* of Glasgow about the year 1861, has three cylinders, one high and two low-pressure, placed side by side, with all three piston-rods attached to one cross-head. It has recently been very satisfactorily

* See correction as to this, p. 481 infra. 
applied to paddle steamers of large power by Messrs. Douglas Hebson and W. G. Ramsden of Liverpool, as shown in Figs. 8 and 9, Plate 59. In this case the steeple form of engine is adopted; the three cylinders of each engine are firmly bolted both to each other, and to keelsons fore and aft the vessel, thus forming a very solid and substantial base upon which to construct the upper framing. Each set of cylinders is worked by one valve and motion, Marshall's arrangement being used. The three piston-rods are attached to the moving cross-head, and guided in the usual way.

This engine, the writer believes, is a novelty as thus applied. It can be made to weigh no more than the oscillating form; it has given most satisfactory economical results in working; it is easy to maintain, and affords great facility of access to all the working parts for overhauling and repair, when required.

The most recent form of compound engine, introduced into our transatlantic steamships, has three cylinders, one high-pressure between two low-pressure, having an intermediate receiver, and working into one crank-shaft, having three cranks placed at equal angles from each other. This description of engine, Figs. 10 and 11, Plate 60, bids fair to become the favourite one for large powers; several are now at work, and give unqualified satisfaction both as to economy of fuel and cheapness of maintenance. The Arizona, of the Guion line, one of the first constructed on this plan, has worked so well hitherto that her owners have since ordered others of greater power of the same description. The Servia also, now being finished for the Cunard line, has engines of this kind, with cylinders one of $72 \mathrm{in.} \mathrm{and} \mathrm{two} \mathrm{of} 100 \mathrm{in}$. diameter, and $6 \frac{1}{2} \mathrm{ft}$. stroke. Compared with the triple tandem engines of the City of Rome, these have only half the number of cylinders, pistons, valves, valve-rods, and appurtenances, to get ont of order and keep in repair; while the balance of strains on the main shafting and crank-pins can be readily equalised by adjusting the cut-off of steam.

These three great types of compound engines may be placed as follows, in the order of their general acceptance by the shipowning community. 
1. The two-cylinder intermediate-receiver compound engine, Plate 53, having cranks at right angles.

2. The Woolf engine, gonerally in the tandem form, having the high-pressure and low-pressure cylinders in line with each other, Plates 55 and 56, or occasionally having three cylinders alongside, Plate 59, but communicating their power to one crank. A pair of such cylinders is used sometimes singly, Plates 55 and $5 \dot{6}$, oftener two pairs together, Plate 58 , working side by side to cranks at right angles; recently three pairs together, working to cranks placed $120^{\circ}$ apart. The system affords the opportunity of adding yet more engines to the same propeller to an indefinite extent.

3. The three-cylinder intermediate-receiver compound engine, Plate 60, with one high and two low-pressure cylinders, the steam passing from the high-pressure cylinder into the receiver, and thence into the two low-pressure cylinders respectively. The cranks are placed at equal angles apart round the crank-shaft, so as to balance the forces exerted upon the shaft.

These three types may be said to embrace all the engines now being manufactured in this country for the propulsion of steam vessels by the screw propeller. In their leading principles they also embrace nearly all paddle-engines now being built, whether the cylinders be oscillating, fixed vertically, or inclined to the shaft.

The compound engine in fact, in one of these three forms, may now be said to be universally adopted in this country; and the question of the relative value of simple expansion in one cylinder, and of compound expansion in two or more cylindors, which agitated the minds of some of our leading engineers ten years ago, is now practically solved in favour of the latter.

The Marine Boiler of to-day is in all its main features the same as it was ten years ago.

The single-ended boiler, shown in Plate 61, and made with two, three, and sometimes four furnaces, is the simplest form, and, for all powers under and including 500 I.H.P. is the most generally adopted.

The double-ended form, shown in Plates 62 and 63, is largely used. It has been found more economically efficient than the single-ended 
form, by as much as 10 per cent. in the writer's own experience. It is generally adopted for engines of large power, but for small powers is inconvenient, owing to its occupying more room lengthwise in the vessel, and also involving two stoke-holds and therefore more supervision. At one time great difficulty was found in keeping the bottoms of boilers of this kind tight. Owing to their length, the unequal expansion due to different temperatures at the top and bottom caused severe racking strains on the bottom seams and riveting-so severe in some cases as to rend the plating for a large part of the bottom circumference of the shell. This difficulty has now been to a large extent got over, in consequence of the greater attention given to the form and direction of the water spaces in the boiler itself, so as to induce circulation of water; the introduction of the feed-water at the top instead of near the bottom; the more careful management now usual on the part of engineers; and lastly, the use of larger plates, welded horizontal seams, drilled rivet holes, and more perfect workmanship throughout.

In boilers having a single flame-box to two furnaces opposite each other, as in Fig. 19, Plate 63, difficulty has been experienced in keeping the ends of the tubes tight, owing to the action of the one furnace upon the other, and the inequalities of temperature induced thereby. This is now obviated by the introduction of a fire-brick division extending just so high as to prevent the current of air, when the door is opened, from striking directly upon the opposite tube-plate.

The modification of double-ended boiler shown in Figs. 20 and 21, Plate 64, is that introduced by Mr. Alfred Holt. It has many decided advantages, but is costly to make. The formation of the two ends into separate fire-boxes leaves the bottom of the boiler free to adapt itself to the variations of temperature to which it is exposed. The separation of the furnaces from the combustion chamber, excepting through the opening afforded by the connecting-tube shown at $A$, is an advantage in the same direction, and avoids almost entirely the racking strains due to irregular furnace action. The weight of water carried is less, and that of the boiler may aJso be made less; while the elliptical form of the two ends gives greater steam space. 
Figs. 24 and 25, Plate 65, represent a type of boiler largely used in Her Majesty's navy, and very suitable for all classes of vessels where length is available. It is introduced here as a specimen of a lighly efficient boiler in regard to weight and power developed. Many examples have yielded one I.H.P. in the cylinders for every $3 \mathrm{sq}$. ft. of heating surface, under natural draught and with a very moderate height of funnel; and this with a consumption of fuel not exceeding $2 \frac{1}{2}$ lbs. per I.H.P. per hour under a working pressure of $60 \mathrm{lbs}$. With the aid of a steam jet in the funnel, the heating surface per I.H.P. has fallen below $2 \frac{1}{2}$ sq. ft. The large water-surface afforded for escape of steam secures almost entire freedom from priming, without the incumbrance of steam domes; and the large combustion chamber allows of the thorough combustion of the gases before their passage through the tubes.

The locomotive type of boiler has lately occupied the writer's attention, with a view to its more definite introduction into marine work. In his recent paper before the Institution of Civil Engineers (Proceedings, 1881, vol. 1xvi., p. 87,) Mr. Thornycroft has shown what can be done with it under a forced draught; and how to reduce the weight of boilers and the water in them, as well as how to get a large power out of a small boiler. This form of boiler, Figs. 22 and 23, Plate 65, affords the opportunity of introducing an almost unlimited amount of absorbing surface in the shape of tubes, while the fire-box is in the best form possible for efficiency. The difficulties however, which lie in the way of applying the same principles to steamers going long voyages, are very great. The principal difficulty lies in the necessity of burning a large quantity of fuel in a very limited space and time. This can only be done either by direct pressure or exhaust action applied at the furnace. In other words we must either exhaust the funnel, which will absorb a large amount of power, but would be comparatively easy of application ; or our stokers, as is the case with our miners, must work under a pressure of air. The writer would submit for the consideration of the meeting whether this latter is an unreasonable condition of things to contemplate, considering that by so doing we should enormously reduce the dead weight of our boilers and water, and thereby leave room for a corresponding wieight of cargo. 
The Perkins boiler (described in Proceedings 1877, p. 117 and Plates 15 to 17 ) may be referred to as a specimen of the tubulous system applied to marine purposes. It must be admitted that the tubulous system has not been a success, as actually worked on board ship; the writer nevertheless submits that this system affords a means of reducing the enormous weight of boilers and water at present deemed necessary, which is well worthy our consideration; more especially as, with increasing steam pressures, this weight must be still further increased, to the serious hindrance of progress, and loss to the shipowner by the displacement of freight-paying cargo.

With regard to the use of steel in marine boilers, the valuable paper read by Mr. Boyd in 1878 and that read by Professor Kennedy at the last meeting have left very little to be said as to the character and use of the material, and the mode of treating it. The writer wishes only to state the result of his experience in the manufacture and working of such boilers, with the view principally of removing the doubt and uncertainty, so freely expressed in the discussion on those papers, and to some extent justified by the failure of the boilers of the Livadia. Many steel boilers of sizes varying from $6 \mathrm{ft}$. to $14 \mathrm{ft} .6$ in. diameter have left Messrs. R. and W. Hawthorn's works at St. Peter's since 1877, when the first was made; and in no case has there been a failure of a plate after being put into a boiler, either in the process of manufacture or in working at sea. The mode of working is as follows:-For shell plates, from $\frac{5}{8}$ in. to $\frac{7}{8}$ in. thick, to warm each to a dark red heat before bending in the rolls, having previously drilled a few holes to template for bolting the plates together; the longitudinal seams are usually lap joints treble-riveted, requiring the corners to be thinned, which is done after rolling, as shown in Figs. 35 to 38, Plate 70. The furnace plates, Plates 61, 62,63 , and 65 , are generally welded longitudinally, two rings in the length of the furnace, and flanged to form Adamson rings, and at the back end to meet the tube-plate; the back flame-box plates are flanged, as also the tube-plates and front and back plates; and wherever work is put on to the plate it is annealed before going into place. The rivet boles are drilled throughout. In putting together the longitudinal seams of the thicker shell plates, great care is always 
taken to set the upper and under plates for the lap to their proper angle before they are bolted together, a point generally overlooked by the practical boilersmith. It will be observed that if this is not done, great strain is thrown on the material, sometimes resulting in fracture; since the plates tend to take the form shown by the dotted lines, Figs. 37 and 38, Plate 70. In two boilers, made in another department of the works, fracture actually did take place while closing up the riveting in four plates $\frac{3}{4}$ in. thick; the riveters having followed the old bad custom, so common in iron boilers, of drawing the plates together when in place, in order to close work which the platers should have closed. The writer suggests that this may have been done in other boilers besides those mentioned. The use of steel for boilers is always recommended by the writer, and in no case has he had cause to regret it.

The question of corrosion is one which is gradually being answered as time goes on; and so far very satisfactorily for steel. Some steel boilers were examined a few weeks ago which were amongst the first made; and the superintending engineer reports, "There is no sign of pitting or corrosion in any part of the boiler; the boilers are washed out very carefully every voyage, and very carefully examined, and I cannot trace anything either leaking or eating away. No zinc is used, only care in washing out, drying out, and managing the water."

This is the evidence of an engineer with a large number of vessels in his charge. His statements could be corroborated by many other engineers in similar positions. On the other hand some of our most prominent Liverpool engineers always use zinc, and take care to apply it most strictly. The evidence of one of them is as follows:- " We always fix slabs of zine to most boilers, exposing not less than a surface of $1 \mathrm{sq}$. ft. for every 20 I.H.P., and distributed throughout the boiler. This zinc we find to be in a state of oxide and crumbling away in about three months. We then renew the whole, and find this will last twelve months or more, when it is renewed again. Meantime we have no pitting and no corrosion, but on the contrary the interior surfaces appear to have taken a coating of oxide of zine all over, and we have no trouble with them." Again many engineers have trouble with their boilers under both systems; 
this is due no doubt to some mismanagement, probably the admission of too much air with the feed water. Frequently too the tubes and interior surfaces are destroyed by drops of moisture being allowed to form and dry upon them, after blowing oat.

The superheating of steam, notwithstanding its undoubted value in all expansion engines, has practically died out. To some extent the use of much higher pressures has rendered it less necessary; but the practical difficulty in the rapid corrosion of the material of which the superheaters were made, and the restrictions imposed by Lloyd's and the Board of Trade on that account, have mainly led to their abandonment.

The most noteworthy feature of to-day in connection with the marine engine is the demand for largely increased power, to meet the requirements of shipowners for larger vessels and higher speeds. There is a growing feeling amongst them that "speed pays"; and that it is better to ensure certainty of arrival at the port of destination than to save a few tons of coal on the voyage. At the same time it is of the utmost importance that the required increase of speed and power should be achieved, first, with the least possible weight of machinery, water, and fuel to be carried; secondly, with the least possible expenditure of fuel; and thirdly, with safety and efficiency in working, low wear and tear, and chenpness of maintenance.

These points being kept in view, the writer proposes to consider our present marine engine as to its efficiency and capability of further improvement, and then to consider generally in what direction we may look for further development; carefully separating, throughout, the boiler, or steam generator, from the engine, or steam user.

Weight.-The weight of machinery, water, and fuel carried for propelling ships has not bad due attention in the general practice of engineers.

By the best shipping authorities the writer is assured that every ton of dead-weight capacity is worth on an average $£ 10$ per annum as earning freight. Assuming therefore the weight of the machinery 
and water in any ordinary vessel to be 300 tons, and that, by careful design and judicious use of materials, the engineer can reduce it by 100 tons, without increasing the cost of working, he makes the vessel worth $£ 1000$ per annum more to her owners. That there is much room for improvement in this direction is shown by the following statement, giving, for various classes of ships, the average weight of machinery, including encines, boilers, water, and all fittings ready for sea, in lbs. per indicated horse power :-

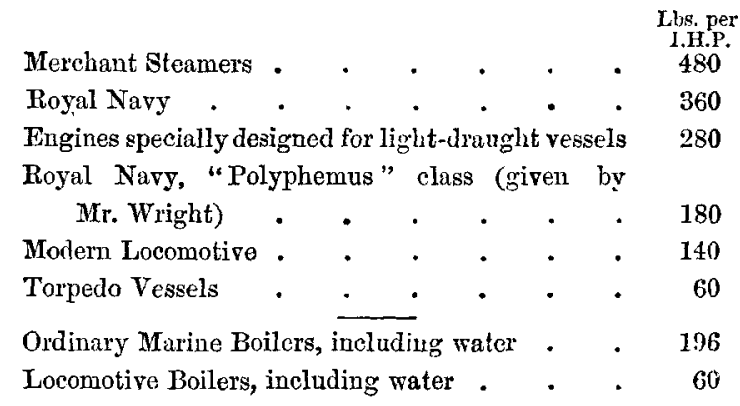

In view of the commercial considerations before mentioned, in regard to merchant steamers, these figures confirm the idea that the weight of machinery on board such vessels has not received the attention its importance demands.

The ordinary marine boiler, encumbered as it is by the Regulations of the Board of 'Trade and of Lloyd's Committee, does not admit of much reduction in the weight of material or of water carried when working. The introduction of steel has reduced the weight by about one-tenth; but it is the alteration of form, to the locomotive, tubulous, or some other type, combined with some method of forced draught, to which we must look for such reductions in weight of material and water as will be of any great commercial value.

The engine may be reduced in weight by reducing its size, and this can only be done by increasing the number of revolutions per minute. It has hitherto been the practice to treat the propeller as dependent upon the size of engines, draught of water, and speed required. This process should be reversed. The propeller's diameter depends on the column of water behind, which is necessary 
to overcome the resistance in front due to the properties of the vessel. This fixed, the intended speed will then fix the number of revolutions, which will be found much greater than is usual in practice; and from this the size of the engines and boilers will be determined.

Great saving in weight can be effected by careful design, and by judicions selection and adaptation of materials; also by the substitution of trussed framing and a proper mode of securing the engine to the structure of the vessel (as worked out in H.M.S. Nelson, by Mr. A. C. Kirk of Glasgow, Plate 66, and in the beautifully designed torpedo-boat engines of Mr. Thornycroft, Plate 67), in place of the massive cast-iron bedplates and columns of the ordinary engines of commerce. The American engines of the earlier time might also be profitably studied, not for imitation throughout, but to see what can be done towards lightening machinery, and at the same time securing efficiency and durability. Condensers may advantageously be made of plate iron, brass, or copper, due care being taken to guard against galvanic action. The condensing surface needs further consideration; in many cases it is much larger than necessary: in which case massive castings of great weight are required, and large quantities of watcr carried, which are not really needed.

The same may be said of the moving parts. Solidity and rigidity are great virtues in a stationary engine or machine, and weight is necessary to the locomotive for the purpose of adbesion; but in the case of a marine engine mass and rigidity may, and frequently do, become serious evils. Firstly, unnecessary mass means needless weight to be carried, unprofitable load to be propelled, and the displacement of its equivalent in freight-paying cargo ; and secondly, it means rigidity, and the setting up of a state of heterogeneity in the whole structure, consisting of ship, engines, and cargo, instead of the homogeneity which is essential to a successful working machine. In fine, the hull and engine should be as much as possible one structure: rigidity in one place and elasticity in others is the cause of most of the accidents so costly to the shipowner. Under such conditions mass and solidity cease to be virtues, and the sooner their place is taken by careful design, and the use of the smallest 
weight of material (of the very best kind for the purpose) consistent with thorough efficiency, the better for all concerned.

Fuel.-We come now to the question of the consumption of fuel. Referring again to Table I. (p. 452) we see that a considerable saving has been effected in nine years. The averages of Sir Frederick Bramwell's Table and of Table I. stand as in Table II. below:-

TABLE II.-Comparison of 1872 aNd 1881.

\begin{tabular}{|c|c|c|}
\hline IтEM. & 1872. & 1881. \\
\hline Boiler pressure, lbs. per sq. in. . & 52.4 & $77 \cdot 4$ \\
Heating surface per I.H.P., sq. ft.. & 4.41 & 3.919 \\
Piston speed, ft. per min. . . . & 376 & 467 \\
Coal burnt per I.H.P.per hour, lbs. & $2 \cdot 11$ & 1.828 \\
\hline
\end{tabular}

This shows a saving equal to $13 \cdot 37$ per cent. in quantity of fuel consumed. It is right to mention that the percentage here stated by no means represents the actual saving effected in money value. The coal now supplied to steamers is of very inferior quality compared with that shipped as bunker coal prior to the coal famine of 1873 and 1874. During those years the refuse of the pits and pit heaps, and the poorest of black material, came into use, and this still holds its place firmly as bunker coal; at best unscreened coal is supplied, where the very best screened coal was required prior to 1873 . This very materially affects the question in hand, and the writer submits that it would not be unrensonable to take credit for a saving in money value of at least 20 per cent., instead of 13 per cont.

The writer thinks it right to introduce at this point a letter with which he has been favoured by Mr. Alfred Holt, of Liverpool, bearing on this subject, as well as on other matters which will be dealt with presently.

"Dear Sir,

“ 1, India Buildings, Liverpool, June 18th, 1881.

"In response to your letter of May $27 \mathrm{th}$, I now enclose the form you sent me, filled up with particulars of specimens of two of 
my best classes of ships. My vessels run in classes, so there is no occasion to give you particulars of individual ships.

"I do not think that quite so good a result as that shown in the form is generally attained on the average through the fleet; and having commenced lately to allow more steam in the high-pressure cylinders, a less economical performance naturally results. I think I should be able to obtain about $2 \cdot 3$ lbs. per I.H.P. per hour over the whole, and $I$ do not think that $I$ have made anything more than a fractional advance in economy of fuel since 1868.

"The fact of the matter is I have not tried to do so, and I don't believe, so far as my observation extends, that mere economy of fuel is much cared for now ; coals, which used to be the greatest, are becoming one of the minor disbursements of a steamer, and it cannot have escaped your notice that some modern steamers, careless of fuel, are actually abandoning both the compound system and high pressure.

"My opinion is, and for many years has been, that the compound system will come to be abandoned. I am endeavouring to feel my way to using the steam in one cylinder only, and so far the results have been encouraging; and I am now engining a 2200 ton vessel on that system. I am also endearouring to do without a crank-shaft, the forward end of the screw-sbaft carrying an ordinary crank with overhung pin. This experiment also, so far as I have got, promises satisfactorily.*

"In my opinion the great improvement of the immediate future is to increase the steam production of our boilers. One ton weight of a locomotive boiler produces as much steam as 6 tons of an ordinary steamboat boiler.

"Of course the solution lies in the possibility of (1) burning more fuel, and (2) taking the heat out of it. It is a difficult problem; a steam blast will not do it, and I am fitting a vessel with a rotary Ulower, capable of a pressure of about 2 lbs. on the inch, which shall cject air through a tapered blast-pipe up the centre line of an ordinary funnel, so near the top that, before the cold ejected air destroys by its gravity the motive force it has received from the blower, and

* This engine, and its general arrangement in the ship, is shown in Figs. 29 to 34 , Plates 68 to 70, from tracings kindly supplied by Mr. Holt. 
so deadens the current, it shall be out of the chimney. At the present time $I$ am more hopeful than confident of the result, but $I$ am convinced improvement in that line is shortly to be looked for. What a gain it would be to diminish the weight of our boilers to one third, which is my aim in the boat alluded to.

"F. C. Marshall, Esq., Newcastle-on-Tyne."

"Yours truly,

"ALFRED Holt."

This letter the writer considers to be of great importance, coming as it does from one of our most enterprising shipowners, who is at the same time an experienced practical engineer.

It will be noticed Mr. Holt speaks of the coal account as one of the minor disbursements of a steamer. He does not give the ratio which coals bear to the total disbursements, but from other reliable sources the writer finds that, according to the direction of the voyage, it varies from 16 to 20 per cent.-or say an average of 18 per cent.-in a vessel carrying a cargo of 2500 tons. This will represent to-day about $£ 3000$ per annum, and in 1872 , at equal prices, the cost would have been $£ 3750$ - showing a saving of $£ 750$, equal to a dividend of say 3 per cent. on the value of the ship. Again, the cost of coal per mile run for such a vessel in 1872 would have been at least $16 \frac{1}{2} d$.; to-day it does not exceed $13 d$.

Viewed from the shipowners' stand-point this may be a minor consideration, but to the marine engineer it is important as indicating progress where progress is difficult; and taking it as such he is encouraged to further effort in the same direction.

Efficiency.-The third part of this question must now be considered, viz. how to increase speed and power with safety and efficiency.

The marine boiler as now made is a very efficient generator. Tables I. and II. show that with an increase of pressure, consumption has been reduced; but if the quantity of steam used be considered, in relation to the increased pressure, it will be seen that the boiler of to-day is little if any more efficient than that of ten years ago: as is shown by the following comparative Table of the calculated advantage due to using steam of the average working 
pressure given in Table $\mathrm{I}$, or $77.4 \mathrm{lbs}$, as compared with the average pressure of 1872 , namely $52.4 \mathrm{lbs}$. The advantage is seen to be 13 per cent., which is almost exactly the same as the actual saving found from Table I.; whence it would appear that our gain in consumption is solely due to higher pressure, and in no sense to increased efficiency of boiler.

\section{TABLE III.}

Calculated net Coal and Steam used per I.H.P. per hour, for steam of 52.4 lbs. and 77.4 lbs. pressure above atm.; the same terminal and back pressure being assumed in each case.

\begin{tabular}{|c|c|c|}
\hline & $\begin{array}{c}\text { Pressure a bove atm. } \\
\mathbf{5 2} \cdot 4 \mathrm{lbs} .\end{array}$ & $\begin{array}{c}\text { Pressure above atm } \\
77^{\circ} 4 \mathrm{lbs} .\end{array}$ \\
\hline 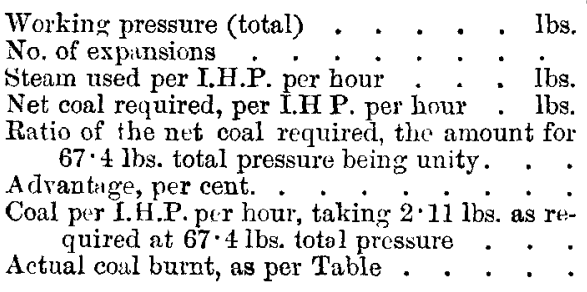 & $\begin{array}{c}67 \cdot 4 \\
5 \cdot 15 \\
21 \cdot 00 \\
1 \cdot 73 \\
1 \cdot 00 \\
\cdots \\
2 \cdot 11 \\
2 \cdot 11\end{array}$ & $\begin{array}{r}92 \cdot 4 \\
7 \cdot 05 \\
18 \cdot 17 \\
1 \cdot 501 \\
0 \cdot 87 \\
13 \\
1 \cdot 835 \\
1 \cdot 828\end{array}$ \\
\hline
\end{tabular}

If the evaporative performance of the marine boiler is to be increased, it must be by one of the four following methods: (1) Increase of heating surface; (2) Better disposition of absorbing surface; (3) The adoption of thinner plates, or of a material laving better conductive power for heat; (4) The adoption of a different and better form of boiler as a whole.

The present boiler has an evaporative efficiendy of about 75 per cent., and cannot be much improved so long as air is supplied to the furnace merely by the natural draught, due to the temperature and height of chimney. The extent of efficient heating and grate surface is limitcd, and almost fixed, by the same cause.

To increase the efficiency by one-tenth, or from 75 to 82.5 per cent., would require about double the heating surface, the weight of boiler and water being also doubled. If it were attempted at the same time to increase the pressure, as well as the heating surface, relatively to the coal burnt, the addition would be somewhat less; 
thus, wore there an increase of pressure from $10 j$ to $150 \mathrm{lbs}$, then, instead of double the quantity of heating surface, $1 \cdot 75$ of that due to the lower pressure would suffice.

Mr. Blechynden's formula, used in the writer's works for weights of cylindrical marine boilers of the ordinary type, and for pressures varying from 50 lbs. to 150 lbs. total, is as follows :-

$$
\mathrm{W}=\frac{(\mathrm{P}+15)\left(\mathrm{S}+\mathrm{D}^{2} \mathrm{~L}\right)}{\mathrm{C}}
$$

$$
\text { whence } W=\frac{2 S(P+15)}{C}
$$

if $\mathrm{S}=\mathrm{D}^{2} \mathrm{~L}$, which is a common proportion.

Here $W=$ weight in tons,

$\mathrm{P}=$ working pressure as on gauge, in 1bs. per sq. in. above atm.,

$\mathrm{S}=$ heating surface, in square feet,

$\mathrm{D}=$ diameter, in feet,

$\mathrm{L}=$ length, in feet,

$\mathbf{C}=\mathbf{a}$ constant divisor, depending on the class of riveting, \&c.

For boilers made to Lloyd's rules, and with iron shells

having 75 per cent. strength of solid plate, $\mathrm{C}=13,200$.

This formula, if correct, and it is almost strictly so, would give the following as relative weights of boilers per sq. $\mathrm{ft}$. of heating surface, for 105 and 150 lbs. total pressure, assuming we wish to increase the efficiency 10 per cent.:-

Weight at $105 \mathrm{lbs} .=105 \times \frac{2 \mathrm{~S}}{\mathrm{U}}$

$$
\Rightarrow \quad 150,=150 \times 1.75 \times \frac{2 \mathrm{~S}}{\mathrm{C}}=263 \times \frac{2 \mathrm{~S}}{\mathrm{C}}
$$

Hence the ratio of weight $=\frac{263}{105}=2 \cdot 5$.

In other words the boiler with the higher efficiency would weigh two-and-a-half times that with the lower efficiency. It appears therefore that increase of efficiency cannot be got to any useful extent by increase of surface, without such serious addition to weight as to render it impracticable, or at least unprofitable.

Next, will better disposition of heating surface, or the adoption of thinner or more conductive material, add to the evaporative efficiency?

It is difficult to see in what way any great departure can be made 
from the present arrangement of surface. The introduction of the Fox corrugated furnace is the only step made of late years, and it promises in the future to be an effective form in which to place the material. Hitherto thero have been-difficulties connected with its use, but these have been in erery case due to manufacture, and such as are incident to overy new process. They have in no case arisen from the principle of corrugation, which must in time permit the furnaces, the best and most vital of the effective parts of the boiler, to be made of considerably thinner plate; and will thus increase to some extent the efficiency of the boiler. The use of metal of higher conductivity for the flame boxes and tubes, say copper for the one and brass for the other, would undoubtedly add greatly to the efficiency of these parts. The boilers of the navy are invariably fitted with brass tubes; and but for the first cost of the material, and subsequent outlay for zine, to prevent galvanie action in the iron plates, it would be a gain to adopt them generally.

We have now considered three of the means of increasing boiler efficiency; but it is clear that anything that can be done with the present boiler is limited by one measure, namely the power of the chimney. Mr. Perkins has shown us that in his boiler, with slow combustion, he can develop in his engine 106 I.H.P., from $6 \mathrm{co}$ sq. ft. of heating surface, on a consumption of under $1.7 \mathrm{lb}$. per I.H.P. per hour, with a working pressure of 350 lbs. per sq. in, and with a weight of boiler and appurtenances-as the writer is informed -only half that of the ordinary form. But it may be doubted whether the tubes forming the furnace, and the rows immediately over the fire, would not very rapidly burn out from the expulsion of the water, under the heat of combustion even of the ordinary 20 to 30 lbs. of fuel burnt, per square foot of grate per hour.

Mr. Perkins has however shown, in the working of his engine and boiler, that cylinders can be worked at $350 \mathrm{lbs}$. pressure and corresponding temperature, without oil or other lubrication than that of the steam itself; and that boilers can be worked at sea with pure water-themselves making up their own waste-and can be kept absolutely clean and free from injurious deposit. These are important gains to our knowledge, and may no doubt bear results in the future. 
The application of forced draught to the furnace has been several times used in maring boilers within the last decade, and promises more than any other method a way to largely increased efficiency, as well as to reduction in weight.

For some fifty years the locomotive boiler has now been in operation, and under the action of the blast pipe has been the most powerful evaporator in existence for its weight. As has been already noted, it does the same work on less than one-third of the weight of the marine boiler. In the case of a vessel of 3000 tons, with engines and boilers of 1500 I.H.P., the introduction of locomotive boilers with forced draught would place at the disposal of the owner 150 tons of cargo space, representing $£ 1500$ per annum in addition to the present earnings of such a vessel. The boiler space of such a ressel, arranged on this principle, is shown in Figs. 39 and 40, Plate 71 : the stoke-hold $\mathrm{S}$ is made air-tight, and two fans $\mathrm{FF}$ are used for forcing the air. The arrangement with the ordinary form of boiler is shown in dotted lines for the purpose of comparison; and the shaded portions AA show the sprees saved by adopting the locomotive type.

Mr. Thornycroft has for some years used the locomotive form of boiler for his steam launches, working them under an air pressuro -produced by a fan discharging into a closed stoke-hold-of from $1 \mathrm{in}$. to 6 in. of water, as may be required. The experiments made gave an evaporation of $7.61 \mathrm{lbs}$. of water, at $212^{\circ} \mathrm{F}$., from $1 \mathrm{lb}$. of coal, with 2 in. of water pressure; and $6 \cdot 41$ lbs. with 6 in. of pressure. These results are low; but it is to be remembered that the heating surfice is necessarily small, in order to save weight, and the temperature of the funnel consequentiy high, ranging from $1073^{\circ} \mathrm{F}$. at the $2 \mathrm{in}$. pressure to $1444^{\circ}$ at the 6 in. With the ordinary proportions of locomotive practice the efficiency can be made equal to the best marine boiler, when working under the water pressure usual in locomotives, say from 3 to 4 in., including funnel draught.

It has recently fallen to the lot of the writer to fit three vessels with boilers worked under pressure in closed stoke-holds. The results, even under unfavourable conditions, were very satisfactory. The pressure of air would be represented by under 2 in. of water, and the I.H.P. given out by the engines was 2800 , as against 1875 when working by natural draught, or exactly 50 per cont. gain in power developed. 
The boilers here alluded to were of the type which, for distinction, may be called the "Navy boiler," Figs. 24 and 25, Plate 65, and they give under ordinary conditions very excellent results. But they have the disadvantage of greater length and weight than the locomotive form, which more than any other, in the writer's opinion, promises to meet the future requirements of the marine engineer.

Two objections to the use of such boilers on board ship have hitherto existed : first, it is supposed they must be deficient in steam room, and therefore very liable to prime; and secondly, there is difficulty in keeping clean, and liability to become salted up.

The first objection is entirely one of construction, and need not exist. The boiler may be made with ample steam room by the addition of a steam dome, or by making the fire-box casing higher than the barrel of the boiler, as shown at $\mathrm{D}$ in Fig. 40, Plate 71, so as to be of sufficient capacity, without increasing the weight of water. The second objection can be met, and is now met in most services, by the increased care now taken by all engineers of their boilers, both in working and when in port. The construction of the boiler need not be such as to make it any less accessible than the present marine boiler; and there is no reason why the water need be worse than that used for locomotives on land. As a rule it is much better, when surface condensers are attended to. The principal difficulty is the "human factor ;" and it must be admitted that marine engineers are much better educated and more intelligent now than ten years ago, and are becoming more and more so. It is also to be considered that, should their responsibility be increased, they are the more likely to become fitted for it.

Great advantages are to be gained by the introduction of a better form of boiler combined with forced draught, and the locomotive form is that presenting the fewest objections.

In referring to the examples given in Table I., it was shown that the saving in fuel actually effected is equal to that calculated to be due to the use of higher working pressures. This indicates that further progress lies in the same direction; although the future saving may be fractional, and cannot possibly equal past results for the same incremonts of pressure. Table IV. opposite shows as follows :- 
TABLE IV.-Quantity of Steam and Coal used per I.H.P. Per hour for Various Working Pressures.

(1) The same Terminal and Back Pressure assumed throughout.

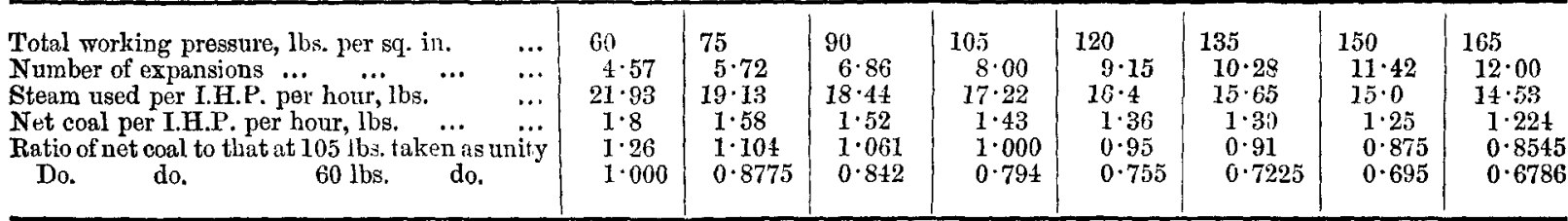

(2) Six Expansions, and the same Back Pressure assumed throughout.

\begin{tabular}{|c|c|c|c|c|c|c|c|c|}
\hline 'I'otal working pressure, lbs. per sq. in. & 60 & 75 & 90 & 105 & 120 & 135 & 150 & 165 \\
\hline Steam used per I.H.P. per hour, lbs. & $19 \cdot 09$ & $18 \cdot 88$ & $18 \cdot 45$ & $18 \cdot 1$ & $17 \cdot 81$ & $17 \cdot 6$ & $17 \cdot 42$ & $17 \cdot 2$ \\
\hline Net coal per I.H.P. per hour, lbs. ... & $1 \cdot 569$ & $1 \cdot 556$ & $1 \cdot 528$ & $1 \cdot 502$ & $1 \cdot 483$ & $1 \cdot 469$ & 1.458 & $1 \cdot 442$ \\
\hline Ratio of net coal to that at I05 Ibs. taken as unit & $1 \cdot 0+3$ & $1 \cdot 0.35$ & $1 \cdot 016$ & $1 \cdot 000$ & 0.988 & $0 \cdot 977$ & 0.97 & $0 \cdot 959$ \\
\hline Do. do. $60 \mathrm{lbs}$. do. & $1 \cdot 000$ & 0.9925 & 0.964 & $0 \cdot 96$ & $0 \cdot 945$ & 0.935 & 0.929 & 0.918 \\
\hline
\end{tabular}

(3) Eight Expansions, and the same Back Pressure assumed throughout.

\begin{tabular}{|c|c|c|c|c|c|c|c|c|}
\hline Total working pressure, lbs. per sq. in. & 60 & 75 & 90 & 105 & 120 & 135 & 150 & 165 \\
\hline Steam used per I.H.P. per hour, lbs. & $18 \cdot 8$ & $18 \cdot 1$ & $17 \cdot 64$ & $17 \cdot 21$ & 17 & $16 \cdot 65$ & $16 \cdot 5$ & $16 \cdot 39$ \\
\hline Net coal per I.H.P. per hour, lbs. $\quad \ldots \quad$... & $1 \cdot 544$ & $1 \cdot \overline{4} 91$ & $1 \cdot 459$ & $1 \cdot 429$ & $1 \cdot 415$ & $1 \cdot 388$ & $1 \cdot 38$ & $1 \cdot 373$ \\
\hline Ratio of net coal to that at 105 lbs. taken as unity & $1 \cdot 053$ & 1.043 &.$I \cdot 021$ & $l \cdot 000$ & $0 \cdot 991$ & 0.972 & $0 \cdot 966$ & $0 \cdot 962$ \\
\hline do $60 \mathrm{lbs}$ do. & $1 \cdot 000$ & $0 \cdot 966$ & 0.945 & 0.925 & 0.917 & 0.897 & $0 \cdot 894$ & 0.89 \\
\hline
\end{tabular}


1st. The quantity of steam and coal used at pressures varying from four to eleven atmospheros, assuming the ratio of expansion to be varied so as to produce the same terminal and back pressure;

2nd. The same, assuming six expansions and the same back pressure ;

3rd. The same, assuming eight expansions and the same back pressure.

The total working pressure of to-day may be accepted as 105 lbs., or equal to seven atmospheres. If it were boldly accepted that eleven atmospheres, or $165 \mathrm{lbs}$, should be the standard working pressure, the best result, with twelve expansions, would be a saving in fuel of 14.55 per cent., provided no counteracting influence came into play. Of course, there are forces which war against the attainment of this advantage to its full extent, viz., the greater condensation in the cylinders and loss in the receiver or passages.

In regard to condensation in the cylinders, it may be questioned whether by steam-jacketing the high-pressure cylinder, correctly proportioning the steam passages, and giving a due amount of compression in both cylinders, this may not be reduced far below the generally received notion; and the loss in the receiver and passages may be considerably reduced in its effect by a more carefully chosen cylinder ratio. The ratio usually adopted, between 3.5 and 4 to 1 , whether the pressure be 70 or 90 lbs., may well be questioned, in view of the results shown in the case of Nos. 6, 15, and 17 in Table I. (p. 452). There, with a cylinder ratio of 2.95 to 1 , the economic performance is very good, and equal to any with the higher ratio; and it may be added that these three cases quoted are amongst the most reliable and trustworthy of the list.

A lower cylinder ratio has another advantage of considerable value, viz., that the working pressure can be much reduced as the boilers get older, while by giving a greater amount of steam the power may be maintained-at an extra cost of steam, of course, but not so great a cost as with higher ratios. This fact was mentioned by $\mathrm{Mr}$. McFarlane Gray in the discussion on Sir Frederick Bramwell's paper in 1872.

The starting has usually fixed the cut-off in the high-pressure cylinder at about 06 of the stroke, and the ratio of expansion has 
decided the ratio of cylinders. The use of separate starting valves in both cylinders obviates that necessity. The difficulties in the way of taking advantage of the higher economic properties of pressures above those hitherto used on board ship, are, it is submitted, not insuperable, and it would be to the interest of all that they should be firmly and determinedly met.

The quantity of steam used in the compound receiver engine and Woolf engine, respectively, are stated by Mr. D. K. Clark in his Manual of Rules, Tables, and Data to be-

Reciver Engine 18 to 20 lbs. per I.H.P. per hour.

Woolf Engine 20 to 21 lbs. per I.H.P. per hour.

It is a remarkable coincidence that the long-voyage results, given in Table I., exactly confirm Mr. Clark's figures. It may therefore be accepted as an average result that the Woolf engine, as usually arranged, will use 10 per cent. more steam than the receiver engine for the same power. For the three-cylinder receiver type the data are insufficient to form a definite opinion upon; but so far the general working of the Arizona is stated to be as good, economically, as in any of the two-cylinder receiver class.

.. It is only right to mention here that the results referred to are very seriously affected by the condition of the valves and gear at the time; and still more by the setting of the valves, and the relations of the admission, port-opening, release, and compression, to the movements of the piston. The efficiency of an engine may be reduced enormously by carelessness in this respect, and when efficiency is of such vital importance, these matters of detail cannot be too strongly urged upon steam-ship owners. It is not too much to say that ninetenths of the engineers in charge of engines know nothing of the condition of their valves, and it is not till some serious waste or mishap occurs that they are thought of.*

* The subject of valve motions was so fully discussed at the Barrow meeting (Proceedings 1880, pp. 418-454) that it is unnecessary to go over the ground agaiv. Those members who are interested may see a model and photographs exhibiting the application of that modification of the Hackworth motion adopted by the writer. It is now at work in thirty-two sets of engines, and is being fitted to as many more by his own and other firms. It is working very satisfactorily in every instance. 
The Surface Condenser remains as it was ten years ago, with scarcely a detail altered. In most engines it remains a portion of the framing, and as such adds greatly to the weight of the engine. It is a question seriously worth consideration whether or no the area of tubesurface can be reduced. The practice at present is to make the condensing surface one-half the heating surface as a minimum, that is, equal to about 2 sq. ft. per I.H.P. In practice, the writer has found 1.4 sq. ft. per I.H.P. to maintain a steady vacuum of $27 \frac{1}{2}$ in. The only experiments on this subject of a practical and accurate character are those conducted by Mr. B. G. Nichol, of Neweastle, an account of which appeared in "Engineering" of 10 th December, 1875. It was found that, when the water flowed through horizontal brass tubes with a velocity of $78 \mathrm{ft}$. per minute, $1 \mathrm{sq}$. ft. was quite sufficient to transfer 533 units of heat per hour from the vapour of the condenser to the water, for each degree Fahr. of effective difference of temperature. Now in general we only have 200 units transferred for each degree of effective difference; so that, even with water flowing through at the slow velocity named, there is a large margin for the dirt frequently found in the tubes of condensers. Then again, an engine using $22 \mathrm{lbs}$. of steam per I.H.P. per hour must require more surfacethan one using $16 \mathrm{lbs}$; and if $2 \mathrm{sq}$. ft. per I.H.P. be necessary for $22 \mathrm{lbs}$, while, by increasing the initial pressure, the quantity of steam can be reduced to $16 \mathrm{lbs}$., we should only require 1.45 sq. $\mathrm{ft}$. per I.H.P. to give the same vacuum, if the condensing water remained the same.

The method generally in use, of passing the water through the inside of the tubes, is much more efficacious than passing the exhaust through them, as is sometimes done in H.M. Nary. The circulation is never so perfect in the latter case, and much more water is carried. The ordinary plan gives more control over the quantity, and also better circulation of the water.

The air and circulating pumps, for engines of 1500 I.H.P. and under, are as a rule worked entirely by levers attached to the lowpressure connecting-rod cross-head. They thus help to balance the piston and rods of that cylinder. The circulating pump is made single or double acting; the single-acting has the advantage of adding to the balancing of the weights, and offers no obstruction to the flow of 
water; the double-acting has the effect of checking the column at each stroke, and is not so easy in working.

The Gwynne centrifugal pump is extensively used for circulating and bilge purposes, and is a very valuable aaxiliary to the main engine pumps.

The extended use of steel offers great advantages in the reducing of weights, and especially in the form of hollow shafts, such as are now being manufactured by $\mathrm{Sir} J$ oseph Whitworth and Co. On this system, in a 10-inch shaft, a hole is run $4 \mathrm{in}$. in diameter, reducing its weight 16 per cent., while its strength is only reduced 2.56 per cent.; or, if the hole were increased to 5 in., the weight would be reduced 25 per cent. and the strength only 4.25 per cent.; and it is a question whether the weight could not be further reduced by giving a lower nominal margin of safety, which it would seem might be done on account of the greater elasticity of form, as well as elasticity and homogeneity of material. The surface presented by a steel shaft to the bearings is also-it is not too much to say-almost infinitely more perfect than by the forged iron shaft, with its reeds, open texture, and iron cinder, from which marine engineers suffer so much. The friction must therefore be greatly reduced.

The writer has just completed six pairs of engines for three twinscrew ships, having steel shafts of 10 inches diameter, and has in each case run the engines at 120 revolutions per minute, while indicating 1380 H.P. from each pair, for ten to fifteen hours without stopping; and in no case has a single bearing or crank-pin warmed or had water applied, the surfaces on examination being perfect.

In these engines all working bolts, pins, and rods, except the piston-rods and connecting-rods, are of steel, all rods in tension being loaded to 8000 lbs. per sq. in. The boilers are of the Navy type, made throughont of Siemens-Martin steel plates, riveted with steel rivets, all holes drilled. The furnaces are welded and flanged; the trabes are of brass. In comparison with an ordinary merchant steamer's iron boilers of the double-ended type, their weight, including water and all appurtenances, and their other particulars, are as follows:-

$\begin{array}{lcc} & \text { Double-ended Type. } & \text { Navy Type. } \\ \text { Weight, tons } & 135 & 146 \\ \text { I.H.P. } & 1400 & 2760 \\ \text { Draught } & \text { Natural } & \text { Forced. }\end{array}$


The use of steel castings is becoming considerable: they give great strength, but unfortunately the still persistent presence of blow-holes prevents their strength, and their wearing to a polished surface, being relied on to the extent that could be wished.

For our large steamors steel-built crank-shafts must come more and more into use. The constant failure of iron cranks, even when built up, is too serious a question for the shipowner to let alone long. It is important to note Mr. Holt's remarks on his return to the oldfashioned mill-engine form of crank, Figs. 33 and 34, Plate 70. The single bearing of great length on the end of a long length of screw-shafting-the crank-pin with small surface velocity-the simple crank, made; as it can now be made, to be practically solid with the shaft-are all great steps in the way of simplicity; provided only shipowners care to adopt the single engine, which, even if ten $\mathrm{p}(\mathrm{x}$ cent. more costly in fuel, has much to commend it.

The cast-steel propeller blades, introduced by Messrs. Vickers, are being more largely used; the reduction in thickness enables them to be much more easily driven.

The serew propeller is still to a great extent an unsolved problem. Wo have no definite rule by which we can fix the most important factor of the whole, namely the diameter. Mr. Froude has pointed out that by reducing the diameter, and thus the peripheral friction, we can increase the efficioncy; and this is confirmed by the cases of the Iris' screw reduced by $2 \mathrm{ft} .3$ in., and the Arizona's reduced by $2 \mathrm{ft}$. This must of course be qualified by other considerations. The ship has by her form a definite resistance, and a certain speed is required; if the propeller be made too small in diameter, the ship will not be driven at the required speed, except at serious loss in other directions.

This question is too large and complicated to be dealt with here, and should, in the first instance, be made the subject of careful and extended experiment, on which a separate paper should be written. The writer's object is to point out the important bearing the question has upon the marine engine. We have shown the importance of the reduction of weight to the shipowner; the smaller the propeller, the smaller the engine needs to be to drive it, and therefore the less the weight to be carric $d$; but to produce the same result in driving the ship, the propcllor will need to be turned faster; and the faster it 
can be turned, consistent with efficiency and small wear and tear, the better. That in our ordinary practice we are a ling way within our powers, in this latter respect, is proved by the engines of torpedo vessels developing 470 I.H.P., at 443 rev. and $886 \mathrm{ft}$. piston speed per minute; the Iris developing 3857 I.H.P., at 99 rev. and $582 \mathrm{ft}$. of a 75-in. piston per minute; and the recently constructed engines, before alluded to, giving out 1400 I.H.P., at 121 rev. and $724 \mathrm{ft}$. per minute of a 60 -in. piston. To do this however the working parts must be carefully balanced-a matter very much neglected, but neglect of which leads to great wear and tear in shafts, crankpins, \&c. Such effects, not being considered sufficiently in the first instance, are urged against the adoption of higher velocities, not specially in the piston, but, what is far more important, in the speed of revolution; which, as experience is showing us, may be vastly increased to the advantage of all, and specinlly of the shipowner, whose interests it is the first interest of marine engineers to promote.

To sum up the whole. Progress has been made during the past nine years, and in the following particulars.

1. The Power of the Engines made and making shows a great increase.

2. Speeds previously unattainable are now seen to be possible in vessels of all the various classes.

3. The Consumption of Fuel is reduced by $13 \cdot 38$ per cent. on the average; and numbers of vessels are now working on much less coal than that average, while the quality of the coal is in nearly all cases very inferior, so that it is not unfair to take credit for 20 per cent. reduction.

4. The Working Pressures of Steam are much increased on the average, and are still increasing; many steamers now being built for 120 lbs. per sq. in., while 90 lbs. is the standard pressure now required.

As increased pressure means increased efficiency, there does not appear any reason why the standard of $150 \mathrm{lbs}$. should not be sought as that of the future; combined with the adoption of the locomotive 
type of boiler and forced draught. Higher speeds of revolution appear to be desirable, with a view to very great reductions in weight of machinery carried. This implies careful balancing and careful adjustment of all working parts, as well as of the steam, to the work to be done.

The more general introduction of steel in all its varieties is enabling the marine engineer to adopt means tending throughout to lighten working parts, and to increase velocities, in a way he dared not attempt nine years ago.

In conclusion the writer begs to submit this paper to the Institution as a very imperfect résumé of the progress and development of the marine engine, and only as a sequel to that of his distinguished predecessor. His time has not permitted him to go fully into the many questions arising out of the subject, and he asks that the paper may be received only as a basis of discussion by the Institution, many members of which are much better able to deal with the matter than he feels himselî to be.

The writer desires to tender his warmest thanks and acknowledgments to the numerous shipowners, manufacturing engineers, marine superintendents, and others, who have so frocly supplied him with valuable information for this paper, some at considerable expense and trouble. He has also pleasure in ncknowledging the careful assistance rendered by Mr. A. Blechynden, M.I.M.E., in the preparation of the details and calculations of the paper. 


\section{Discussion on The Marne Engine.}

Mr. Marshatl wished to make one remark with reference to the consumption of coal, as shown in the last column but two in Table I. (p. 452). In the steamer No. 39 the consumption in 24 hours was put down at 137 tons; but with better qualities of coal, as he was informed in a letter received that morning from the superintending engineer, 110 tons would be more correct. That confirmed the remark he had made in the paper, namely that 13.37 per cent. saving in fuel, during the last nine years, did not fairly represent the money value, or the real progress, in the economy of fuel. In the case mentioned, there was a difference of 27 tons out of 137 tons, due to the quality of coal; and no doubt the same applied to many others of the cases in Table I. ; so that he thought it was perfectly fair to say the saving of fuel had been 20 per cent. during the last nine years.

Mr. A. C. KIRK thought that they were much indebted to Mr. Marshall for bringing before them a fair résumé of the state of marine engineering at the present time. He had not been able to mark any great step taken within the last nine years; but that was by no means his fault, because the fact was there had been no great step whatever taken during that period. Eugineers had gone on gradually increasing the working pressure; and he ventured to think that with the present compound engines it had been increased quite as far as there was any advantage in doing so. The pressures were such that each of the separate cylinders was now brought nearly to the state of the single cylinder in the old engine, before it was compounded. If full advantage were taken of the present pressure of steam-say $90 \mathrm{lbs}$. or $100 \mathrm{lbs}$. per sq. in.--and a high grade of expansion were used in a two-cylinder compound engine, it would be found that in one or perhaps in both of the cylinders they were doing too much expansion (three times in any one cylinder being as much as ought to be used); or, what was still worse, much of the expansion was got by an inordinate drop of pressure in the receiver. 
In either case the range of temporature in each cylinder was getting too great. About eight years ago, in a ship fitted with Mr. Rowan's boilers, carrying a pressure of $150 \mathrm{lbs}$, it had fallen to his lot to design cylinders with triple expansion; and the results, so far as the engines were concerned, had proved so far satisfactory that at the present moment his own firm were doing the same thing with 125 lbs. pressure in ordinary boilers. He could not at present say anything as to the success of this attempt, but the previous case had been very successful.

As to the consumption of coal, Mr. Marshall's figures pretty fairly represented the average saving in consumption during the last nine years : certainly the consumption was not more than was shown in Table I. (p. 452). He was not prepared to credit anything to the use of inferior coal, because he found that the long-royage ocean steamers, in which the consumption of coal was best tested, always used good Welsh coal. He should not himself put the improvement at more than a reduction from the previous consumption of $2 \mathrm{lbs}$. of coal per indicated horse power per hour to a present consumption of $1.8 \mathrm{lb}$; and considering that the pressure had been increased from 60 up to $90 \mathrm{lbs}$., he did not think the economy in coal had kept pace with the increase in the weight and cost of the engines.

The Woolf engine had been spoken of in the paper (p. 458) in a way that might be slightly confusing. When Messrs. Randolph Elder \& Co. introduced their first compound ongines, those had been what were properly called Woolf engines. The expansion was first carried on in the high-pressure cylinder as far as was desirable, and then in the return stroke the expansion was continued simultaneously in both the high-pressure and the low-pressure cylinder down to the point of suppression. In that engine the temperature of the highpressure cylinder varied through the full range that would occur in an old-fashioned single engine, except the drop in temperature from that of suppression to that of the condenser. While this type was in use, the compound marine engine made but little progress. The results were no doubt better than in the ordinary engine, but they were not what they should be. He believed it was due to the President, Mr. Cowper, that the receiver type of engine had becn 
introduced, and brought prominently before the public.* By that means the range of temperature in the high-pressure cylinder was materially reduced. He wished to draw attention to that point, because Mr. Marshall's idea of a Woolf engine appeared to be rather that of an engine in which the two pistons necessarily moved simultaneously in the same direction, or, as in Mr. Elder's engines, in opposite directions. But the engines shown in Plate 58 were not Woolf engines in the proper sense of the word. They were really two receiver engines, with the two pistons working simultaneously in the same direction. If they were made real Woolf engines, there would in that case be such an enormous clearance between the cylinders that there would be a serions loss of effect.

The paper stated (p. 453) that a tandem engine might be multiplied indefinitely in a ship. But any other kind of engine might also le multiplied indefinitely: he failed to see that that was an advantage belonging to the tandem engine alone. He wished also to correct one slight error in the paper: it was not Mr. David Rowan, but Mr. John M. Rowan, who had introduced the type of three-cylinder engine mentioned on page 453 and shown in Plate 59.

One important point to which the paper had referred was the question of reducing the weight of engines. The engines of the Nelson, shown in Plate 66, had been designed by himself for the Admiralty, and the weight had been a matter of vast importance ; but he had never had an opportunity of introducing the same design in the Merchant Service, and he should think twice before he seriously propounded the idea to a shipownor. It was a very expensive form of engine. True it saved weight; but it was not in every ship that the saving of weight was of value. There was a very large class of ships of which the freight-earning power depended upon how much bulk they could contain in measurement,

* The following note has been supplied by the President. "About 1838 a small steamboat, the Era, had a high and a low-pressure cylinder, with a pipe connecting them, and cranks at right angles; in 1857 a pair of 60 horse-power engines with high and low-pressure cylinders had a steam-jacketed receiver added to them by $\mathbf{E}$. A. Cowper; in 1862 he improved the receiver, and in 1864 he read a paper on Compound Engines at the Institution of Naval Architects." 
not how much dead weight they could carry; and even the owners of ships in which the freight depended simply upon dead weight would think twice before paying anything extra for the engines. He had always found light engines expensive. Their costly workmanship and large amount of high-class material cost more than less costly workmanship and a larger quantity of lower-class material. There was another engine, shown in Plate 67, with wrought-iron frames and diagonals, but stiffened fore and aft instead of athwartship; this however was for a torpedo boat, in which the transverse strains were taken by the hull.

He might be permitted to point out that the three-cylinder compound engine was rather older than Mr. Marshall seemed to be aware. His own impression was that he had first seen it in France; at all events the first examples of that particular type, Plate 60 , but fitted with piston-valves, had been made for the Iberia and the Liguria about 1875. But the late Mr. Elder had made for H.M.S. Constance a three-cylinder compound Woolf engine about the year 1858 or 1859. There were two sorts of three-cylinder compound engines, as there were of two-cylinder engines; but Mr. Elder's was a Woolf engine, having continuous expansion in the high-pressure cylinder.

He would now make a few remarks on the subject of boilers. Unquestionably the type of marine boiler was practically fixed for the present. It was a very good boiler; and with the restrictions due to the somewhat paternal way in which marine boilers were treated, he thought it would be some time before that type was departed from. It certainly would not be seriously departed from unless by some one who had great patience, and was prepared to spend a great deal of money. The locomotive type of boiler was however worthy of the attention that $M_{r}$. Marshall had given to it. It might seem singular, but no shipbuilder would be allowed to take a locomotive engine from a railway station and put it on board a ship to work at the same pressure. It was considered safe enough on land among thousands of people, but it was thought it would not do at sea.

Whether a forced blast was to become a feature of the future boiler for ships going Iong voyages-to Australia for example-he 
was not prepared to say; but there was a class of steamers going short voyages, of very high speed and limited draught of water, where weight must be kept down; and there the forced blast continuously applied was not only admissible, but, he ventured to say, was the only rational solution of the problem.

As to the remark, p. 474, about the two different classes of condensers, one condensing inside the tubes and the other outside, in his opinion it was simply a question of the circulation of the water. The one condenser was as efficient as the other, if the circulation were made alike. Where the water was inside the tubes, it happened to be perfectly easy to secure good circulation; but the other condenser could be made equally good by putting in two or three diaphragms or baffle-plates to direct the water across the tubes.

Attention had been drawn (p. 475) to steel castings, in regard to their saving of weight. In the present ongines that his own firm was building for the Admiralty, and indeed in a previous set, cast-steel pistons had been used. In order to test them, they were bolted together in pairs by the centre, with an india-rubber joint round the circumference, but no bolts to connect them there; and water was pumped into the space between them. They were thus tested at $90 \mathrm{lbs}$. per sq. in., and at that pressure there was no appreciable deflection whatever. They gave no trouble with blowholes in the castings; there were ono or two blow-holes, but they were quite insignificant. He had also used other castings in steellarge eccentrics and so on. The question was one well worthy the attention of marine engineers. Levers, for instance, might be made of cast steel, saving in many cases all the trouble of using plant for forging and machining thern, where it was not necessary to give any high finish.

He thought there was some confusion in regard to one statement in the paper, p. $476:$ " the smaller the propeller, the smaller the engine needs to be to drive it, and therefore the less the weight to be carried." But in the Iris the propeller was reduced, keeping the same engine, and a higher speed was obtained with the smallor propeller than with the larger one. He failed to seo that there was any connection between the size of the propeller and the size of 
the engine. A small propeller had naturally a greater pitch given to it, when intended to be driven at the same number of revolutions per minute and to produce the same speed of vessel as a larger propeller; but the reduction in its diameter was made with a view to reduce its friction in the water, and need not involve reducing the size of the engine.

Mr. George Crow had had many years' experience in building single-crank tandem engines of tho class shown in Plates 55 and 50. The paper alluded to the difficulty of handling these engines in starting and stopping (p. 453). He himself generally went to sea with the engines during their trial trips; in all cases he had seen his engines tried, and he could state that there was no difficulty in starting. There had been some difficulty previous to the introduction of good steam reversing gear; but now the man in charge, if a skilful engineer, could work the engines a half stroke or any portion of a revolution, and never allow them to get on the centre, thus working them like a pumping engine. It was true there was what was called a steam turning engine, for the purpose of overhauling the engines in port, and for warning through before putting the main engines under way; but he did not think he had ever seen it used for the purpose of pulling the main engines off the centre, since the application of steam reversing gear.

The paper stated, p. 473 , that "the Woolf engine, as usually arranged, will use 10 per cent. more steam than the receiver engine for the same power." He was at a loss to understand how that could be. In the Woolf engine the steam exhausted direct from the high-pressure down to the low-pressure cylinder, with no chamber between the two ; consequently there was less surface for condensation, both externally and internally. Ho therefore thought it would be difficult for any one to prove that two cylinders side by side, with a receiver between, could be more economical in fuel. If true, it could not result from the arrangement of the engine, but from somo other cause. The last engine he had made of the class referred to was for the screw steamer Tega, sailing to Calcutta for Messrs. Rathbone, Liverpool, carrying a dead-weight cargo of fully 3,500 
tons, and of 1,600 I.H.P.; and she averaged for the entire run $11 \frac{1}{2}$ knots per hour, consuming $1 \frac{3}{4} \mathrm{lb}$. of coal per I.H.P. per hour.

Mr. John Rogkrson was very glad Mr. Marshall had brought forward his paper, as he had taken the opportunity of consulting that gentleman, for the last twenty years and more, on the building of engines and boilers. He thought it was only fair to refer to one point mentioned in the paper in relation to the Perkins boiler, p. 458: "It must be admitted that the tubulous system has not been a success." Now the Perkins system had as yet been tried to a very limited extent only. In the case of the Emily, Mr. Perkins stated that it had becn a success; and the Anthracite, built upon the Tyne -a small boat $60 \mathrm{ft}$. long-had gone to London and then across to America and back, with a vory small consumption of fuel; and he believed she had given every satisfaction to the builders. But be wished particularly to refer to the Loftus Perkins, which had been built and run by the Tyne General Ferry Co., as a passenger steamer on the Tyne. The safety-valves were loaded to $450 \mathrm{lbs}$. per sq. in., and the boiler tested to $2000 \mathrm{lbs}$. per sq. in. The engines had three cylinders, one high-pressure $10 \mathrm{in.}$ diameter, one medium $14 \mathrm{in.,} \mathrm{and}$ one low-pressure $28 \mathrm{in}$; the length of stroke was 18 in., and the power 125 I.H.P. The fuel was gas coke; and the consumption under trial in a day's work of thirteen hours was $25 \mathrm{cwt}$. or $1.72 \mathrm{lb}$. per I.H.P. per hour. The vessel had run with passengers ninety-one days, making in all 5,582 miles, in addition to a great number of trial trips. After this period, during six months of which a Board of Trade certificate for passengers had been held, the boiler tubes were drilled for the surveyors to examine, and proved perfectly clean and free from scale. The consumption of second-class steam coals in other boats doing the same work, with ordinary oscillating engines, was 3.09 lbs. per I.H.P. per hour, or 45 cwt. per day, costing 13s. $6 d$, as against $68.3 d$. for the Loftus Perlins : showing a saving in favour of the lattcr of 44 per cent. in weight of fuel, and 54 per cent. in cost of fuel. There was a defect in the engines, but it was a mechanical defect, arising from the boat being very limited in size, and did not affect the system. He believed a boat on this system 
was now running between Greenock and Belfast, and was proving that the system was one of the most economical in regard to the consumption of fuel.

In reference to the use of steel castings, the complaint made as to blow-holes might be sometimes well founded; but it was not so in all cases. Steel castings, such as Attwood's castings, as now made in the district of Newcastle, were perfectly solid, and no blow-holes could be seen in them.

Sir F. J. Brayweth said there was one question that lay at the root of the matter of fuel consumption, both as stated in the paper and as presented by himself at the meeting of the Institution in Liverpool in 1872; namely, how was the gross indicated horsepower ascertained? in other words, what was the divisor used for the coal consumed? He thought this really ought to be known in each case; because, if the gross horse-power indicated, say upon a trial trip, were used for the divisor of the coal consumed during a voyage, results might be arrived at which were not accurate. The last speaker had alluded tó some of Mr. Perkins's boats. He himself might perhaps be permitted to mention that in the case of the recent trial of the Anthracite (after her vojage to and from America) conducted by Mr. W. E. Rich and himself, and in the presence of Mr. Thornycroft, the method pursued to obtain a trustworthy result was as follows. Indicator diagrams were taken every half hour until they ceased to put coal upon the fire; then they were taken every quarter of an hour; and then, when the engines fell off from their normal speed, they were taken every five minutes until the engines came to a stand. It might interest the meeting to know that Mr. Thornycroft, who at this time went into the boiler room to seo how much fire remained on the bars, found the fire-box in complete darkness, and had to take a light to look for what was left of the fuel; this was found to be only a few cinders, so cold that they could be carried in the hand. The engines worked until the effective boiler pressure had fallen to zero, at which time they came to a dead stand, having just before been making from 28 to 30 revolntions per minute. The time of running was 12 hours and 10 minutes. Every 
pound of coal used in getting up steam and consumed during the run was debited to the engine; and the total foot-pounds exerted in the 12 hours being known, a proper divisor and dividend were obtained. The resulting quotient was $1.79 \mathrm{lb}$. per I.H.P. per hour, including the getting up of steam; while, omitting the getting up of steam, and assuming the fire to have been in the same state at the end of 7 hours' work out of the 12 as it was at the beginning, the consumption in that time was $1.66 \mathrm{lb}$. per I.H.P. per hour.

He wished to refer to one other matter in that boat, namely the condenser, which he considered to be of an extremely good construction. The arrangement was that of vertical close-topped tubes, having open-ended tubes within them. The close-topped tubes terminated at their bottom ends in one tube-plate, and the openended tubes in another. The condensing water went up through the open-ended tubes and then came down through the annular space between the two tubes, and all difficulties of expansion were got over. A steady vacuum was maintained of $28 \frac{3}{4}$ to 29 inches of mercury the whole time.

There was one other point to be referred to, namely that of the forced draught now being adopted. He had previously stated to the Institution that he had seen used in America in 1853, in paddle steamers burning anthracite coal, a system of forced draught, with the stoke-hold under pressure. He did not think there could be any practical objection to it; on the contrary, he should think the men in the stoke-hold would be glad of anything that would ensure to them sufficient ventilation.

Mr. W. Parker said he agreed generally with what Mr. Marshall had laid before them in his valuable paper, so far as the reduction of consumption was concerned. As regarded the reduction of 50 per cent. referred to by Mr. Marshall, and also mentioned in the discussion upon Sir F. Bramwell's paper in 1872 as having been obtained in the preceding nine years, he thought it would be freely acknowledged to have been due to the general adoption of the surface condenser and the compound engine. A similar reduction could not be expected in the following nine years; still, as Mr. 
Marshall had shown, a reduction had steadily gone on. The paper stated the reduction at $13 \cdot 37$ per cent., and this on the assumption that the pressure had reached only $77 \mathrm{lbs}$. This was no doubt the average pressure for the several vessels referred to in Mr. Marshall's paper; but for boilers now being built he ventured to say that $77 \mathrm{lbs}$. was nothing like the avernge pressure: $90 \mathrm{lbs}$, would be very much nearer the mark. In estimating the reduction of fuel consumption obtained during the last nine years, it was not only the average pressure in a number of steamers actually running which should be taken, but also the maximum pressure; and every one would admit that 100 lbs. was now becoming a common pressure. The introduction of steel and of corrugated furnaces had led to an increase of pressure equal to at least 33 per cent.: this had taken place within the last $2 \frac{1}{2}$ years, and he ventured to think that if, instead of the average pressure, Mr. Marshall had taken into consideration the maximum pressure given by those improvements, the saving of fuel shown would have been fully 15 per cent., instead of 13.37 per cent., as compared with 1872 . Instead of considering that they had got to the end of their tether, he thought they could still go somewhat further in this direction. It had been suggested at some of their meetings that boiler shells might be constructed in solid rings. If that could be done-and eminent steel-makers said it was quite possible-there would be another increase of pressure of 25 per cent.; because the strength of a boiler shell was of course governcd by the strength of the seam, and it was impossible to obtain, even by double-riveting, above 75 per cent. of the strength of the solid plate; hence if the plate were solid, there could be at least another 25 per cent. increase of pressure.

He rose however chiefly in consequence of a remark in the paper about the restrictions imposed by Lloyd's Register, and by the Board of Trade. He hardly expected to hear that from Mr. Marshall, who he thought had given them credit at Lloyd's for not trying to obstruct, but rather striving to promote progress. There were certain lifferences betwecn the rules of Lloyd's Register and the rules of the Board of Trade, which he might explain, as they had been commonted unon by several engineers in the district. The strength 
required in a cylindrical boiler shell had been laid down by the Board of Trade to be six times the working pressure. Thus the shell of a boiler to work at 100 lbs. should not burst at less than than $600 \mathrm{Ibs}$. At the present time engineers were testing the material used in these shells, so that such a high factor as 6 was not required to cover any inequality of material. Again, they had tested so many seams that they knew from calculation the strength of the seam as compared with the solid plate; so that the factor of safety of 6 was not required to cover any defect in the construction. The only other element appeared to him to be corrosion. Now corrosion, every one would admit, was a constant quantity, whether in a thick or a thin plate; and if a factor of 6 was found to be quite sufficient for thin plates, he submitted that for thick plates it was altogether too high. The loss of $\frac{1}{8}$-in. on a $\frac{3}{8}$-in. shell plate would reduce the strength of the structure one-third, whilst the same amount of corrosion on a 1-in. plate would reduce it only one-eighth. Lloyd's rules took cognisance of this difference, which the rules of the Board of Trade did not provide for.

Mr. Marshall had referred to the large steamers now being constructed. Just now they were on the eve of a very great experiment. The Servia, the City of Rome, and the Alaska would in a few months be racing across the Atlantic; the powers to be exerted by them were unprecedented; nothing of the kind had been witnessed in the mercantile marine; and all were looking forward with great interest to the results that would be obtained by these huge vessels. It would hardly be right to criticise those vessels before they began to run; but he nevertheless believed that if those vessels, which were going to transmit such enormous power through a single screw, had been made with two screws, a better result might be obtained.

Mr. W. E. RICH said that the author's valuable paper showed an immense amount of labour in collecting and tabulating the statistics brought forward; and he had also given them the benefit of his large experience in discussing the present condition and probable future development of the marine engine. With regard 
to Table I. (p. 452) he ventured, with Sir Frederick Bramwell, to doubt the extreme figures that were there given. They would all alike rejoice when they had indubitable evidence of a consumption of only $1.5 \mathrm{lb}$. of coal per I.H.P. per hour, as recorded in the Table, either in marine or in land engines; but he feared that result was not nearly attained yet. $\mathrm{He}$ had of late years tried many experiments with land engines on the compound principle, having every provision about them to ensure economic working; and he must say he had failed to obtain a lower consumption than 2 lbs. of coal per I.H.P. per hour. This led him to suspect that only the best engines ten years ago worked with $2 \cdot 1 \mathrm{lbs}$, and only the best now with $1.8 \mathrm{lb}$. He should like to know, as well as the coal, the weight of steam used per I.H.P.; then they would be able to determine how much of the improved economy of late years was due to the modern compound engine, and how much to the higher pressure in the boiler. They could then determine also the relative merits of the locomotive and other types of boiler, so far as ecomomy was concerned. Mechanical questions must affect the construction of a boiler, as well as those of economy; but he believed the locomotive type to be one of the best for obtaining a large weight of steam per pound of coal burnt in the fire-box. They had seen what had been done by portable engines, which had boilers of the locomotive type.

With regard to the question of mechanical effiency, what was wanted was not only to indicate great power in the engines, but to get as much of that power as possible upon the screw-propeller; and he was afraid they were still considerably in the dark as to how much of the power developed in the engines got through to the screwpropeller. The late Mr. Froude's marine dynamometer had, he believed, only been tried once. Having attended that trial at Devonport, he believed it would become a most valuable instrument when there had been a little more experience in its use. Mr. Edward Froude had told him, a few weeks ago, that he did not consider the statistics of the first trial satisfactory enough to be placed before the world, but he hoped to make other trials with the instrument soon. During the one trial already made, the power diagram showed 
a succession of waves of delicately refined outline, one wave being described for each revolution. The shape of the wave varied very much with the ratio of expansion; and he believed that such wave outlines would tell a great deal as to the effects of vibration \&e. upon the screw-propeller shaft, and as to economy in the propulsion of vessels.

The President, in his opening address, in speaking of some of the modern improvements in marine engineering, had referred to Mr. David Joy's valve-gear. Such types of gear were certainly very interesting. He learnt that Mr. Marshall had fitted thirty vessels with his own gear, which were all doing well. It was certainly a step in advance in marine engineering to seo such forms of valve-gear coming to the front; and one great advantage derivable from them was the getting of all the expansion desired, with a single slide-valve.

Another point of importance in large engines was the introduction of piston-valves, which appeared to be very much in vogue among the Clyde shipbuilders; if experience gave good results with those valves, he thought they would come to be much more used than they now were. The high-pressure steam-valves in Mr. Perkins' experimental steamer Anthracite were peculiar, being cast-iron mitre valves, unbalanced, and working on cast-iron seats, with a small lift and feather guides. They worked extremely well, and after going to America and back the engines seemed to give excellent results with them. One could not hear them work, when going at 110 revolutions per minute.

With reference to surface condensers, he agreed with Mr. Marshall that even now the surface might be very much reduced. It was only natural to expect that, in proportion as engines used steam more economically, condensing surface might be reduced; and even more than in direct proportion, because the steam would leave the cylinders at a lower temperature.

Mr. B. G. NrchoL thought the present discussion would serve as a landmark in the history of the marine engine. So far as. he had been able to judge, there appeared to be three distinct views before 
the meeting. The first was enunciated in the letter written by Mr. Holt, namely that the compound engine would be abandoned, and a return be made either to a simple pair of expansive engines or to a single engine. Then there was a second view, which he might call the "finality" view, entnciated in the remarks of Mr. Kirk: and no doubt the present compound engine was a very perfect machine. The third view was that enunciated in the paper, which boldly launched out into speculation, and suggested the direction of future improvement.

With regard to Mr. Holt's view, he thought there was much to be said in its favour. In the first place the engine was reduced to its simplest form ; and a further point might be mentioned in its favour, namely the results obtained in America with long-stroke engines, where the diameter was very small in proportion to the stroke, and consequently the clearance spaces, and the amount of surface exposed at the ends of the stroke to the condenser, were very small in relation to the steam admission. But the same argument might also be used in favour of the present compound engines-that if the length of stroke were increased there was no question but that a still higher amount of efficiency would be attained. As to the present engine, the results in Table I. (p. 452) were most excellent. From the averages of the figures quoted, he made out that there was an efficiency aue to the boiler of nearly 75 per cent.; whence, assuming the full value of $1 \mathrm{lb}$. of coal to be $13 \frac{1}{2} \mathrm{lbs}$. of water evaporated from $212^{\circ} \mathrm{Fahr}$. at atmospheric pressure, the boiler efficiency would be $10.06 \mathrm{lbs}$. of water so evaporated per lb. of coal; or $8.75 \mathrm{lbs}$. evaporated under the mean boiler pressure as given, of 77.4 lbs. per sq. in. above atmosphere, with feed water entering at $100^{\circ}$. Then 8.75 multiplied by the mean consumption of $1.828 \mathrm{lb}$. of coal gave nearly $16 \mathrm{lbs}$. weight of steam per I.H.P. per hour, which was certainly a very excellent result; and he doubted very much whether an engine could be made to use steam more economically than that. He agreed with Mr. Marshall however that the boiler afforded ample room for improvement. He thought the direction indicated-working under a pressure of air--seemed to point to an unmixed good, enabling the weight both of the boiler 
and of the water carried to be reduced greatly. Seeing that Mr. Marshall had obtained with forced draught nearly 50 per cent. more power than with the natural draught, he thought it was certainly worth a trial on a large scale in the mercantile marine.

There was one more point to which he should like to call attention, as to the coal used per I.H.P. There ought to be some standard to work to, which should be taken as unity, and should be the result obtained under the best conditions; and then what was obtained in actual working would be some percentage of that standard. He had been investigating for some time the coal used by two or three lines of steamers, and he lad found that when the coal was supplied in English ports the work done and the expenditure of coal practically agreed. Using Atherton's rule, namely the cube of the speed multiplied into the two-thirds power of the displacement, and divided by the hundredweights of coal per hour, a certain constant was obtained; and that constant, for a speed of 9 knots an hour, was practically correct at 12,400 for north-country coal, and at 13,500 for Welsh coal. But when vessels proceeded to the Mediterranean, or to the Indian ports, and there took coal on board, the constant often fell as low as 8,000 , when worked out in the same way; showing clearly that the full weight was never supplied, unless very great care was taken to obtain what was actually paid for. In one instance the constant showed during one voyage 14 per cent. short weight, and the report was sent to the captain and engineer of the steamer. The ship went on the same voyage again, and instead of having 14 per cent. or 160 tons short in a seven months' voyage, there was less than 3 per cent. unaccounted for. That was a matier which ought to be taken into consideration, when shipowners came to examine their coal bills.

Mr. Samson Fox thought from what the author had said, p. 468 , that he was rather in the dark as to the number of corrugated flues which had been made. They had now been made to the number of 3,700, two-thirds in marine and one-third in land boilers, and the number of failures amounted in all to eight. One steamer and two land boilers had given out in the flues; a flue had 
collapsed on account of being red hot; another on account of running very short voyages, and not being sufficiently washed out. The oldest flues had been at work about four years; therefore with regard to the question of endurance there was, he thought, sufficient evidence. With regard to the evaporative power, he could give a comparison of one or two large steamers, indicating between 3,000 and 4,000 horse-power. In the case of two steamers built exactly alike, except that one had plain furnaces and the other corrugated furnaces, the indication of the former was a little over 3,500 horsepower, and of the latter just 4,000 horse-power. In the case of another pair, the difference in favour of the corrugated furnace was about 450 horse-power out of 3,750 . Then as to economy, there was a steamer which had been running a voyage of something like 12,000 miles for about three years: the area of the fire-grate in that set of boilers was $273 \mathrm{sq}$. $\mathrm{ft}$., and the horse-power indicated was 2,677 ; the mean speed of the ship was 13.1 knots per hour, and the consumption of fuel over the whole of the time was $1.67 \mathrm{lb}$. per I.H.P. per hour. With regard to land boilers, a very accurate test had been made in Germany: a boiler $30 \mathrm{ft}$. long, $7 \mathrm{ft} .2 \mathrm{in}$. diameter, and with a flue $4 \mathrm{ft} .3 \mathrm{in}$. diameter, with the feedwater at $131^{\circ}$ Fahr., evaporated 10.85 lbs. of water per $\mathrm{lb}$. of coal, at a steam pressure of $75 \mathrm{lbs}$. per sq. in. After that an experiment was tried by shutting off the external flues at the sides of the boiler, and using oniy the $30 \mathrm{ft}$. corrugated flue; the evaporation was then $8.175 \mathrm{lbs}$. of water per $\mathrm{lb}$. of coal, or nearly $6 \mathrm{lbs}$. of water per sq. $\mathrm{ft}$. of flue surface per hour. The corrugated flue, both in its manufacture and in its use, had presented difficulties which were not easy to be got over, from the material first used having been iron; and he was satisfied that, unless he had taken to mild steel, the corrugated flue would have had many diffeulties to contend with, which had now been got rid of. Iron manufactured in large plates could not be thoroughly homogeneous. The best method of making iron, up to the present day, was that of puddling and piling slab moulds one upon another and welding; and its success depended on the complete welding up of all the original surfaces of the slabs. Now a plate sufficient to make a flue of $16 \mathrm{cwt}$. required a pile of at least 
20 slabs weighing 1 cwt. each, and each having a surface of about 3 sq. ft.; and it would be found a very difficult job in practice to get rid of those $60 \mathrm{sq}$. ft. of surface, so as to have a homogeneous plate. But with mild steel an ingot was taken, in which the particles had never separated since they had come together in the mould; and the only difficulty was in the ends. He had made above 2,000 tons of steel ingots into corrugated flues, and not five plates made from those ingots had been rejected, though every plate had been tested by the Board of Trade.

Mr. Jeremiah Head, referring to the paragraph (p. 4.66) "If the evaporative performance of the marine boiler is to be increased, it must be by one of the four following methods," thought perhaps a fifth might have been added, namely a greater difference of temperature between the inside of the fire-box and the water spaces. Every one knew that if two bodies at different temperatures were in contact, the heat passed from the one to the other with a velocity of transmission varying as the square root of the difference between the temperatures. In drawing attention to the saving of fuel which had been effected during the last nine years, the author had pointed out that the mean pressure used had increased from an average of $60 \mathrm{lbs}$. to something like $100 \mathrm{lbs}$. Now, inasmuch as water or steam at 100 lbs. pressure was of a considerably higher temperature than water or steam at $60 \mathrm{lbs}$., it was clear that, if the temperature in the fire-box was not altered--the method of burning the coal remaining the same,- - there was now actually less difference than before between the temperature of the fire-box and that of the water to which the heat had to be imparted. Therefore it would be strange if the boiler had even maintained its efficiency during this period, seeing that there had been less difference of temperature for the transmission of heat. Evidently this point had been perceived by the author and some of the previous speakers, because they advocated strongly a forced blast, which meant a higher temperature in the fire-box; but it did not appear to him that that was clearly brought out in the paragraph, p. 466. He should therefore like to suggest that the reason why the forced blast was so likely to be the real direction of 
improvement was that every square foot of heating surface would thereby become very much more effective, because of the greater difference of temperature, and the greater velocity in transmission of heat, thereby produced. If higher pressures were to be used, and therefore higher temperatures of water in the boiler, it was clear that the way in which progress must be made in efficiency was by getting a higher temperature in the fire-box; and the best way at present known for doing this was by means of a forced blast.

There was another direction in which he was sanguine that something might be done at some future time. Every ton of air that entered the fire-box was composed, roughly speaking, of about onefifth oxygen and four-fifths nitrogen. That nitrogen was inert and useless; it entered the fire-box say at a temperature of $50^{\circ} \mathrm{Fahr}$., and left the funnel afterwards at $600^{\circ}$, and it was clear that the whole of the heat taken up by it as it passed through the fire-box and tubes was entirely lost. A plan was needed, which should save passing that useless nitrogen through the fire-box. He believed some experiments had been made some jears since, to see if ordinary atmospheric air could not to some extent be filtered of the nitrogen, by passing it through something which would take a little of it away, so as to leave the air that had passed through richer in oxygen than before. It had been found that by passing air through very fine membranes of a certain kind the nitrogen was stopped more than the oxygen was. Perhaps, if it could not be done in that way, it might be done by artificially mixing the air to some extent with oxygen before it entered the ash-pit, in such a way as to increase its richness. Or there was still another way in which the same end might be reached, namely by some regenerative system. If the air which entered the ash-pit could be heated beforehand by the waste heat from the funnel, it would effect what was needed by lessening the total amount of heat which was run away with by the nitrogen.

Speaking of the joints in a boiler, Mr. Parker had said that if the external rings of the boiler could be rolled solid, without any joint, 25 per cent. more pressure might be used, because the joints were never more than 75 per cent. as strong as the solid plate. He would suggest whether Mr. Parker did not forget the crossing of 
the joints. Supposing the whole length of the boiler was made of four rings breaking joint, the boiler was not weakened to the full extent of the difference between the joint and the solid, but only by something like half that difference, or $12 \frac{1}{2}$ per cent. Mr. Parker had also spoken about the factor of safety which should be allowed for thick and for thin plates; but he would ask whether he had considered that thick plates, whether in iron or steel, were not quite as strong (so far as they now knew how to make them) as thinner plates, on account of the smaller amount of work, relatively, which it was practicable to put upon thera ; and therefore whether the factor of safety should after all be altered. Mr. Parker had also said, with regard to the factor of safety of 6 , that it had only to cover the corrosion. But he would suggest whether it was not the elastic limit which should be considered, and not merely the ultimate tensile strength. If it was true, as had been shown at the last meeting (Proceedings, 1881, p. 209), that steel began to stretch permanently at only a little over 8 tons per sq. in,, which was something like one-fourth of its ultimate tensile strength, then, inasmuch as they must not exceed or even come near that elastic limit, he would ask whether 6 was really too high a factor of safety.

Mr. T. R. Crampron said the author had brought the subject forward in a very clear way, in expressing his views as to what should be done in the future. But in one point lee had not done what he ought to have done-namely to separate the boiler from the engine. He did not see how any satisfactory judgment could be formed unless these were separated. He had known cases in which good engines had been condemned in consequence of the boiler, and the converse. About forty years ago he had made experiments with 40 lbs. pressure and about six grades of expansion, on a doublecylinder compound engine well jacketed, and everything attended to as well as it was in the present day; and one I.H.P. was obtained from $18 \mathrm{lbs}$. of water. He felt convinced that practically $11 \mathrm{lbs}$. of water would very shortly be evaporated with $1 \mathrm{lb}$. of Newcastle coal. It was simply a question of regularity of firing; and that had not been touched at all. There should be some mechanical means of 
firing. As to the reduction of nitrogen, which Mr. Head had suggested, he believed if the nitrogen were reduced they would have too much heat. If the proper proportions were kept, namely $12 \mathrm{lbs}$. of air to $1 \mathrm{lb}$. of fuel, they might even now have a temperature so high that they might prefer to reduce it if anything.

Mr. Holt's idea of having a single engine deserved great consideration. Of course the double engine would naturally give a more equal motion; but if engineers could practically get what they wanted from the single engine, by all means let them keep to it, up to the maximum which it could do. With the single engine the expenses were reduced in a variety of ways, and every part conld be got at better. His conviction was that they ought not to look always to the consumption of fuel, but also to the cost of repairs at the end of five or six years. There were many things to be done besides burning fuel.

With regard to the question of condensing, he might point out that the passing of water through the condensers by pressure gave a better result than by sucking it through. Some experiments which he had made on a marine boiler, with 1,500 sq. ft. of heating surface, showed 10 per cent. more water evaporated by the use of air under pressure than by the vacuum of the ordinary chimney draught. $\mathrm{He}$ had tested the quantity of the gases passing through all the tubes, and had found that in the case of pressure all the tubes were being supplied with the proper quantity of gas, while with suction a large number of the tubes had hardly any gas passing through. The suction of the chimney drew all the gases by the nearest path. There was also another practical advantage when cleaning out the tubes. In the case he had mentioned he had found that, having a pressure of only about $\frac{1}{2}$ inch of water in the fire-box (working with dust-fuel), the smoke-box door could be opened and the tubes cleaned out while working, and the evaporation was only 10 or 15 per cent. less than when working at a maximum with the smoke-box door shut.

From experiments which he had made upon the subject, he. believed there was a future for self-acting firing, thus doing away with the dreadful work of the firemen; and that 11 lbs. of water would then be practically evaporated from $1 \mathrm{lb}$. of coal, as he had done over and over again with self-acting fring, and with dust-fuel. The 
difficulty he had experienced had been in the lining of the fire-box; the great heat destroyed the bricks to such an extent that he had discontinued the experiments. Since then however he thought he had discovered a self-acting lining which could be recuperated, and made practically indestructible. If a revolving fire-box were used, as the bricks wore away they got to a point where the water kept them cool; and if the brick lining was knocked off it was replaced by the slag. If dirt was put in, it would melt, and accumulate in the chamber until it ran over, the dirt in the coal being sufficient for the purpose. There would always be a lining of slag in the chamber; and this was necessary if they used dust fuel. They simply wanted a plain cylindrical boiler, filled with tubes like a locomotive boiler, and having the revolving combustion chamber in the front of it: like his revolving puddling furnace (Proceedings, 1876, Plate 43), where the slag formed a permanent lining. This system of revolving chamber had proved to be almost indestructible in puddling; and was therefore quite adapted for boilers. The form of such a boiler as now described was very simple, and it was excessively strong. He only mentioned the matter to show that under such conditions they might have a perfect self-acting apparatus. The climate was a matter of no consequence; they might start from England and go to Calcutta, and if they wished to burn say 1 ton of coal an hour, they could burn it within 5 per cent. on the whole journey without any one touching the apparatus. He might observe that too little attention had been given to this question of self-acting firing; there had doubtless been many failures, which discouraged steamship owners. The problem was not easy to solve, particularly where fire-bars were a requisite; but with dust-fuel and a revolving fire-box it was, in his opinion, quite possible to effect the object.

Mr. E. ReYnouds wished first to acknowledge the kind way in which Mr. Marshall had mentioned cast-steel propellers: he had been the first to adopt them for ocean ships, and he had been a steady friend to them ever since.

Referring to the question of the single engine, it was practically impossible to put into a ship a fly-wheel which would give an equality of power with an engine of 5,000 or 6,000 H.P. It was 
diffeult enough to get proper work ont of a propeller, even when it had uniform power on it throughout the revolution; and he was satisfied that no fancied simplicity of a single engine would compensate for the disadvantage of applying the power to the propeller by irregular efforts.

With regard to boilers, in the presence of so many marine engineers he did not wish to say much; but there were a few fallacies on that subject to which he wished to call attention. First of all, the disposition to exaggerate the advantage of the locomotive type of boiler was again on the increase. The locomotive boiler he believed was the best for its particular purpose, but its special conditions must be borne in mind. One of these doubtless was to burn a very large quantity of fuel in a small space; and this was becoming daily more desirable in steamboats, as the author had pointed out. But a locomotive boiler was washed out say every two days, and properly looked after; and that condition failing, he did not think that a boiler, with spaces so very narrow as to enable the surface to be concentrated in the way it was in the locomotive, would do at sea: but where the circumstances were such as to admit of crowded heating surface, with very narrow water-spaces and no possibility of internal examination, then other forms of multitubular boilers could be so arranged as easily as the locomotive form. Next, the thinner plates which were used in locomotive boilers, with a lower factor of safety than the Board of Trade required for marine boilers, would not be admissible at sea without constant or very frequent attention. He seldom heard a paper of that kind read without hearing attacks on the factor of 6 , as required for marine boilers. Ho could only say he should be sorry to buy any part of a marine engine in which he imagined there was a lower factor of safety thau 6 , even though so much did not depend on the failure of the engine as on that of the boiler. There was another practical point, namely that when it was attempted to make a boiler of that class to any considerable size-such a size as the marine service would require - the difficulties already felt by locomotive superintendents would become exaggerated. The locomotive fire-box with its flat sides, which could not expand in any way without 
some buckling, was not now the durable affair it used to be when it was only $3 \mathrm{ft}$. square; and the difficulty would keep increasing as the flat sides became larger. He was aware that Mr. Fox had proposed to corrugate those flat sides, something after the fashion of the corrugated flues; but he could not, with the flat sides, get the yielding in every direction that he did get with the cylindrical flue.

With regard to the best type of boiler generally, the effort to reduce the diameter of the shells was by no means new. He remembered Sir Frederick Bramwell many years ago constructing some boilers with small shells and water legs. But one thing which should be borne in mind was that it was not sufficient for the boiler to have merely a certain amount of heating surface in a small space; there must be also a certain area of water surface, especially in a ship tumbling about at sea. Mr. Marshall had called attention to that point, and had claimed it as one of the advantages of the navy boiler, as it unquestionably was; but he seemed to have lost sight of it again a little, because in his proposal to introduce the locomotive type he had mentioned that steam space might be got by raising the crown of the external fire-box. That was not the same thing: steam room and water area were not interchangeable advantages.

Mr. D. Adamson said the point in the paper which specially impressed him was the selection of the type of engine. He thought it was only fair that they should acknowledge amongst themselves the great progress that bad taken place during the last nine years, since Sir Frederick Bramwell's paper had been read. It was stated in the present paper that there had since been an annual saving of $1 \frac{1}{2}$ per cent., or $13 \frac{1}{2}$ per cent. gross in all; and it had been verbally stated, since the paper was read, that the saving was really equal to 2 per cent. per annum. The saving, if it went on at that rate, would be very great, and must end in a very economical consumption of fuel before many years were over. On the type of engine the goodness and the success of a ship greatly depended. The subject had been before them in 1880 at Barrow, and the triple engine had there been recommended; but he thought that Mr. Marshall spoiled his 
paper in some degree by the value be attached to Mr. Holt's letter. For if one cylinder were used to produce the force necessary for propelling a big ship, say equal to a percussive force of 100 tons on the steam piston, was it practical or sensible to bring such a force on a single crank-pin, when it could easily be divided over three cylinders, letting each have a force of only 33 tons? While they got triple security in the triple engine, they would not diminish by a fraction the ultimate strength of the screw-shaft, because that was wanted to contend with the full power of the combined engines. But if it were wished to get the highest possible proportion of power, that would be most easily accomplished, as had been wisely suggested, by a much increased speed of piston. He held that this was the great and only principle to act upon-to angment the bearing surfaces, and to diminish the percussive action and the frictional load on the crankpin as they increased the speed. It was no supposition, it was a demonstrated fact, that the faster any machine went the less force must there be on any given point of wearing surface. As to the question of three cylinders or one cylinder, he held that one cylinder was an inadmissible and an obsolete arrangement. If they looked at the matter according to the one-sided view that Mr. Crampton had put before them, they would at once jump to the conclusion that simplicity was everything; but could any one control the laws of nature and turn them to his own convenience at will? If they began with a high pressure at one end of the stroke, and ended with only atmospheric pressure at the other, the difference of temperature within the one cylinder would preclude any possibility of the economical application of the steam.

It might be remembered that he had read a paper before the Iron and Steel Institute (see Journal 1875, p. 360) on quadruple action, or engines to use steam four times over; and if he were to prophesy with regard to the results, he should certainly prophesy success for quadruple action, with a continuous run-through of the steam from cylinder to cylinder. First, nature was on his side. The temperature was only lowered in a slight degree in each successive cylinder. Beginning say with 100 lbs. to 120 lbs. on the first piston (which was his common practice), the pressure on the second piston would probably 
be about 60 to $65 \mathrm{lbs}$. The reduction in temperature in any one cylinder was very much less than could possibly be the case if the entire expansion took place in one cylinder, when commencing with $120 \mathrm{lbs}$. pressure; and although there must be some loss between the cylinders, both in pressure and in temperature, it was only slight: while on the other hand the four pistons would check any loss through leakage of steam direct into the condenser, which must take place with one cylinder when either the piston or the slide-valve leaked. Beyond this, he held to the grand principle of Dalton's discovery, and GayLussac's in France-in the same year 1801, although unknown to each other -that by increasing the temperature of gases $480^{\circ} \mathrm{Fahr}$. their volume was doubled. Now multiple cylinders gave facilities for superheating, which were impracticable in the single cylinder. Superheating high-pressure steam could only end as it had done, in extreme failure, since high-pressure steam was necessarily hot steam, and they did not want to make it more impracticable than it already was in that respect; but with the multiple-cylinder system the lowpressure steam could certainly be practically superheated to the temperature of high-pressure steam, whilst the expansion was going on, and concurrently with the reduction of pressure; and thereby considerable economy could be secured in the multiple system, over and above the single-cylinder plan. Steam at atmospheric pressure, or $212^{\circ}$, might be heated up to the temperature of high-pressure steam, or at least to $360^{\circ}$; and superheating became in this way not only practicable but highly economical. Thus they were enabled to utilise Dalton's grand law, and to increase the bulk of the steam at much less cost than by any other means.

Passing on to the consideration of the boiler, the most injurious condition set forth was that of corrosion. He regretted that the paper to follow, on iron and steel for ships, had not been read at the same time as Mr. Marshall's, because it was impossible to consider at all the question of the application of mild steel or iron, without discussing the conditions attached to shipbuilding; but ho would treat of this when Mr. Price's paper came to be read.*

\footnotetext{
* See discussion upon "Iron and Steel for Ships," pp. 571-4, infra.
} 
The subject of riveted joints was of vital importance in connection with steam boilers. But the strength of the joints, in the marine boiler especially, was not of equal importance throughout; there mast be one class of joints for the shell, and another class of joints for the fire-box. With regard to the joints for the shell, it was of no importance to consider the quantity of metal requisite to unite the plates, in order to get up to the maximum strength. The principal thing was to get uniformity of strength throughout. On that head he was inclined to think that the corrugated flue had been rather too strongly put forwards. It had some advantages and some disadvantages, but he would only look at it for the present with regard to the condition of a fire-box which was subject to getting red hot, and needed to have security under those extreme conditions. The corrugated flue, they were told, when red hot collapsed and went down. But in place of corrugated flues, Adamson's flange seams might be used, which might be made as numerous as was wished, and with this difference: that the metal between the flange seams would withstand the force of the pressure, let that pressure be what it might, either at red heat or comparatively white heat, the flanges forming as it were a back-bone between the intermediate plates. Security could thus be obtained, because of the quantity of metal in the flanges that was kept away from the fire, and was exposed only to the temperature of the steam.

Mr. Marshall said he must thank the members cordially for the very candid and friendly manner in which his paper had been discussed. Of course he knew that it had run counter to the views of several friends present, notably perhaps Mr. Crampton, who was always against high pressures. $\mathrm{H}_{\theta}$ would now endeavour to reply to the various questions that had been raised by the several speakers.

First he would thank Mr. Kirk-who he supposed might be looked upon as the representative of the Glasgow engineering and ship-building community-for the remarks he had made. It was satisfactory to find that he approved of pressures of at least $120 \mathrm{lbs}$. He himself did not think there was much gain to be got beyond that pressure, or $150 \mathrm{lbs}$. at the outside. The practical difficulties then 
became so great-as had been seen in the Perkins engine so ably reported upon very recently by Sir Frederick Bramwell-that there was clearly a limit to high pressures. Owing to the multiplication of cylinders, and the difficulty of dealing with high temperature, no higher result had been there found with $390 \mathrm{lbs}$. than was now obtained every day with 90 lbs, pressure.

Mr. Kirk had raised a question to which attention had also been called in the paper-the question of dead-weight capacity instead of measurement capacity; and had mentioned that there were vast numbers of ships that did not measure their profit by dead weight at all. That was quite correct; but, while there were a great many that never went by dead weight, a large proportion of steamships did, as for instance all the Transatlantic steamers, all the vessels going along the coast, and ore- and grain-carrying vessels, of which there were a large number. In those cases, wherever a ton weight was saved in machinery and in water carried, there was $£ 10$ per annum advantage to the shipowner.

Mr. Kirk had also remarked that light engines must necessarily be costly; and he agreed with him. There was not a manufacturing engineer who would not agree that, where they had to use steel and to go into appliances involving a large amount of manufacture and manual labour, the work must be more costly than where they could deal with a heavy casting, which could be taken out of the foundry and simply dropped into its place. Still, if a lighter engine could be constructed, as Mr. Kirk had constructed the engines of the Nelson (which ho believed was a very satisfactory ship), and if Mr. Thornycroft was right in adopting a system of working engines at 600 revolntions per minute, or at 440 in first-class torpedo boats-if that could be done, it was worth doing. The weight was worth saring, and he thought there was a field open for the engineer's skill and ability in that direction. It was a purely mechanical step. It might be costly, and the shipowner would have to pay for it; but supposing a pair of 200 horse engines, suitable for a ship of 3,000 tons doad weight, were to cost $£ 1,000$ more, and would save the owner $£ 1,000$ a year, then he would get the additional expense back in twelve months, with the advantage of the permanently higher profit subsequently. 
He was glad to find that Mr. Kirk concurred in his view in reference to the Iocomotive boiler. Perhaps while referring to that subject it might be well to go into the several questions which had been raised respecting it by the various speakers. The basis on which he had gone was that of efficiency and reduction of weight, with a view of making the marine engine more profitable to the owner. Now, if a locomotive boiler could be adopted for a vessel of say 3,000 tons, requiring engines of 1,500 indicated horse power, as in Plate 71, where the dotted lines showed the space required for boilers of the ordinary type, it would be seen that the locomotive form would save the space $A$ at the fore end, Fig. 40, and also a considerable amount at the sides, Fig. 39. It would save at least 150 tons of cubic capacity in that particular ship, the St. Dunstan; and that saving meant of course $£ 1,500$ a year to tho shipowner.

With regard to the question of water surface, raised by $\mathrm{Mr}$. Reynolds, the water surface in locomotive boilers would not be much less than in the navy form of equal power. The three locomotive boilers shown in Plate 71 had together 242 sq. $\mathrm{ft}$. of water surface, while boilers of the navy form, for the same power, would give about 300 sq. ft. He did not anticipate any difficulty whatever in getting dry steam, bearing in mind locomotive practice, where there was no very serious difficulty with priming or with wet steam. The large steam-chamber $\mathrm{D}$ in the locomotive boiler, Fig. 40, was carried with a view of taking the steam off at as high a point as possible, about $6 \mathrm{ft}$. above the water level.

He should have been glad to hear at greater length the views of members on the subject of forced draught and the mode of appiying it. The part $\mathrm{S}$ in Fig. 40, Plate 71, would be the enclosed stoke-hold, where the men would have to work under pressure from the blowing fans FF. He did not anticipate that the pressure required would be more than $1 \frac{1}{4}$ in. of water column, as in the case of the vessels with forced draught alluded to in the paper, p. 469 ; which, added to the funnel draught, would make an effective pressure of 1.65 inch. The men there worked six or eight hours at a time, without difficulty.

Mr. Crow had stated that the Woolf engine was as efficient as the receiver engine. No doubt there was a difficulty in saying why it 
should not be so ; but the fact was that it was not, if judged by the coal consumed and power indicated. A glance at Table I. (p. 452) would show that the results given for the $B$ (Woolf) and $C$ (receiver) classes of engines differed by exactly 10 per cent. in favour of the receiver class : thus confirming Mr. D. K. Clark's deductions from experiments conducted by the most trustworthy American and French engineers. The difference in actunl working on long sea voyages was thus 10 per cent. He did not say that that was all loss in the Woolf engine; but in his opinion there were no cases in which that class of marine engine was preferable to the receiver engine, in regard to efficiency.

Sir Frederick Bramwell and Mr. Rich had been inclined to call in question the correctness of Table $I$. The data were obtained in this way. He had drawn out a form, and sent it round to a large number of manufacturing engineers, shipowners, marine superintendents and others, who returned it to hin with the data filled in. He had merely asked them to give the best results they had obtained in recert practice in long-voyage ships; and they had supplied the information which he had embodied in the Table. On some occasions, where he had felt doubtful as to the results, he had written a second time about them. When he had received a statement of indicated horse-power in very round numbers, such as 700,800 , or 1000 , he had thought the figure questionable, and had taken the liberty of either rejecting the ship from the list, or calling the attention of those sending the information in order that they might correct it. But in nearly every case the data were so satisfactory that be could not call them in question. The form returned to him was accompanied in many cases by indicator diagrams, giving the steam-pressures and the revolutions of the engines; and also by the logs of the vessels themselves on long voyages. If the revolutions and the indicator card corresponded with the average of the work as recorded in the $\log$, he took that as the soundest and best datum that could be had for the final result. He thought the Table might be considered as giving, not, as Mr. Parker had said, the highest results obtained, but average results, which might be regarded ten years hence by his successor as accurate, in the same sense as he himself regarded those given by Sir Frederick Branwell. 
With referonce to Mr. Perkins's system of tubulous boiler, referred to by Mr. Rogerson and also by Sir Frederick Bramwell, it was clear to him that that boiler had something wrong about it. If there was a pressure of $390 \mathrm{lbs}$. in the boiler, and only $295 \mathrm{lbs}$. in the cylinder, then there must be something wrong somewhere. Then again, in multiplying cylinders and passing the steam from one to another, there seemed to be enormous losses going on between them. Mr. Adamson had called attention to the advantages of multiplying cylinders; but there were certainly also disadvantages attending the plan, and he thought Mr. Perkins had experienced them. At any rate he himself did not see what good was to be got by adopting Mr. Perkins's form of tubulons boiler, if the result was only to be very similar to that generally obtained with the ordinary form of mariue boiler. The difficulty which he saw was that of getting dry steam. Water was carried over with the steam, and efficiency was lost.

Mr. Parker had called attention to some romarks in the paper as "complaining of restrictions." He was not aware that he had complained. He thought the Board of Trade was a very useful institution; and Lloyd's also, especially so long as it was managed by Mr. Parker. He had merely referred to the fact that there were certain restrictions, and that so long as those restrictions remained there was a diffeulty in adopting very freely the locomotive or any other form of boiler. He would give an example. If they were to take the locomotive boiler of to-day, working regularly on the railway (as Mr. Kirk had said), among thousands of people, at $150 \mathrm{lbs}$. or $180 \mathrm{lbs}$, and were to ask the Board of Trade to pass it, they would pass it at something like $90 \mathrm{lbs}$; ; so that half the pressure would be lost. He did not say that Lloyd's were right or wrong in so doing; but it was a restriction.

As to corrugated flues, he thought they were a step in the right direction. He had himself been singularly unfortunate in the use of them, and he had mentioned in the paper the causes of failure. He believed these had not been due to the corrugated principle, but to the difficulties which Mr. Fox himself admitted had been met with in the manufacture. These Mr. Fox was now rapidly 
overcoming; and when he had got his mills to work, and could manufacture the flues by rolling them, as was being done by Krupp at Essen, instead of hammering them as at present, a good furnace would be obtained by the corrugated system, if it were not superseded beforehand by the locomotive boiler.

With regard to the question of the single engine and Mr. Holt's letter, he had called attention to that letter because $\mathrm{Mr}$. Holt was a gentleman well known to many of them as a very advanced shipowner, who did not hesitate to spend his money and use his vessels in experimenting, so as to bring about the best possible results. $\mathrm{He}$ perhaps took therefore a broader view than many marine engineers. He worked the ships himself, and had the question of expenses and repairs constantly before him, as well as the coal account, which he called a minor disbursement; and so long as the engine was managed by him, or by their esteemed friend Mr. Crow under his direction, it seemed to do very good work. Mr. Holt did not attempt anything like a high economical result; he said he did not seek it. He did not know that Mr. Holt was right there; perhaps he was not. A shipowner might as well have the $£ 10$ per annum if he could, instead of the ton of coal to carry; but Mr. Holt did not seem to care for it, and they must leave him to his opinion. 


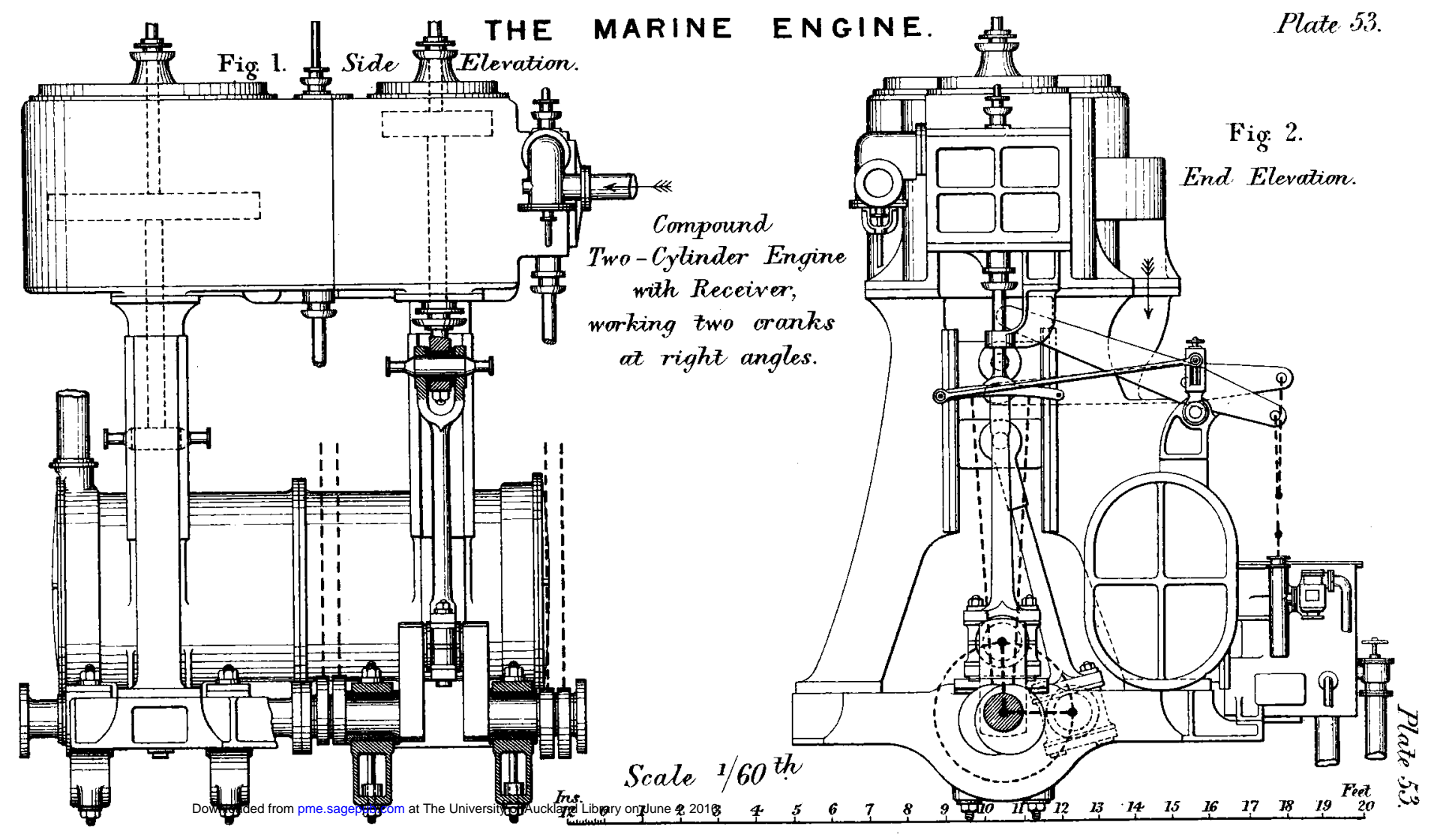




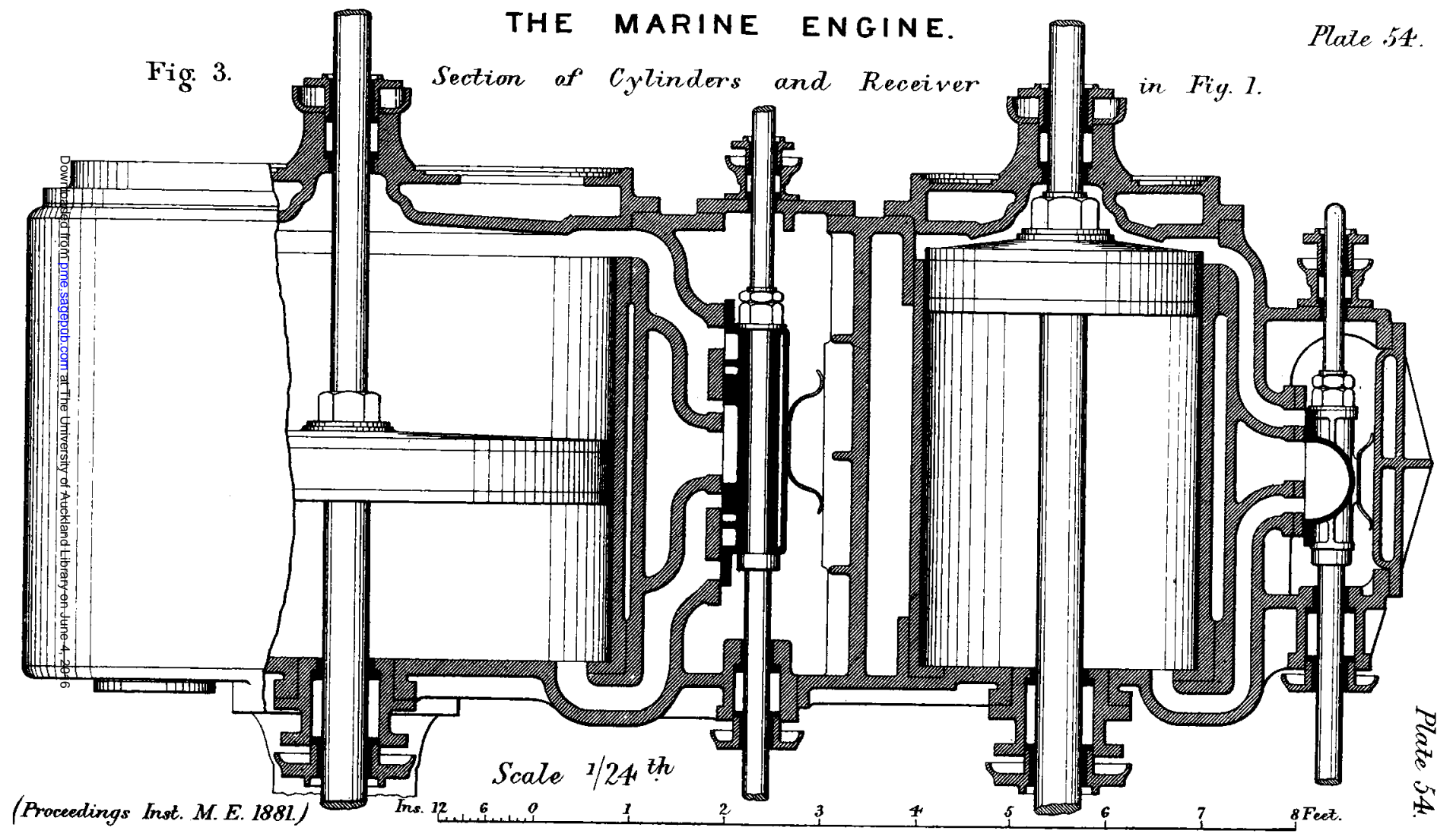


THE MARINE ENGINE. Plaze 55.

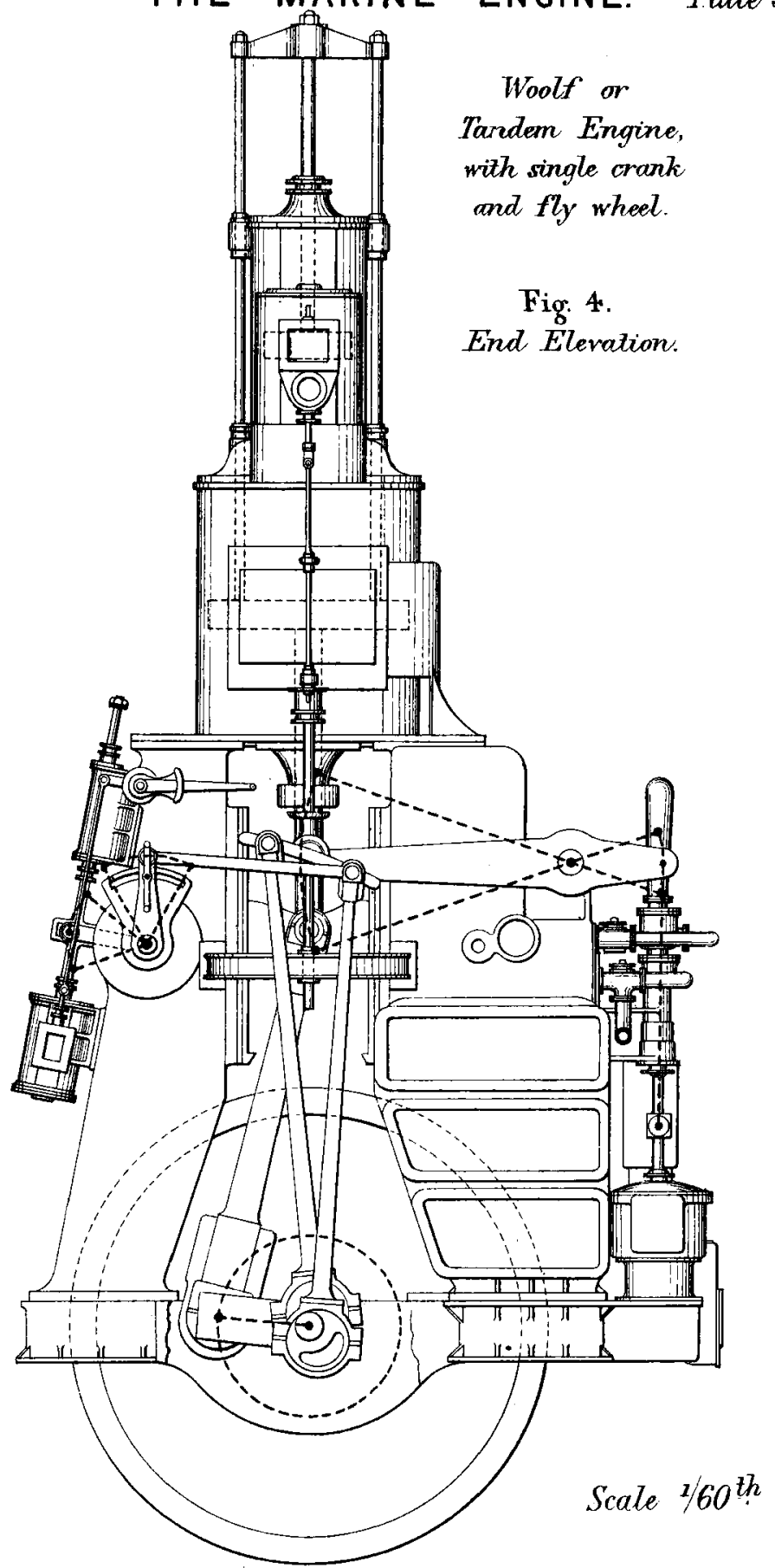

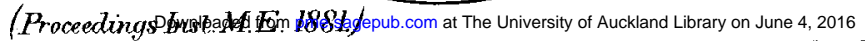

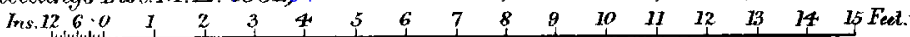


THE MARINE ENGINE. Plate 56.

Woolf or

Tandem Engine, with single crank and fly wheel.
Fig. 5.

Side Elevation.

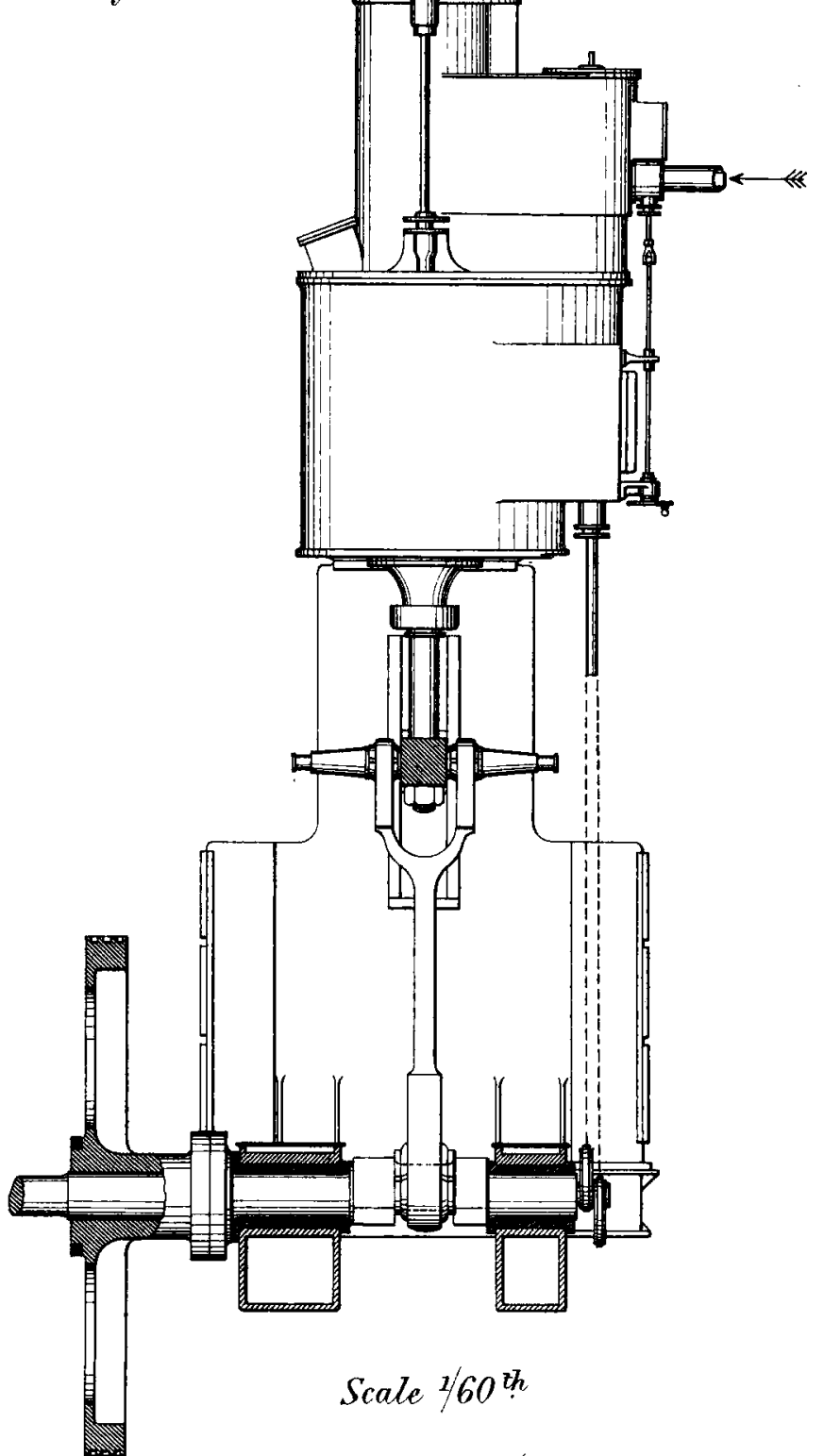

Downloaded from pme.sagepub.com at The University of Auck (F⿻一𠃋

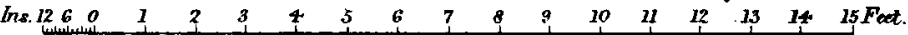




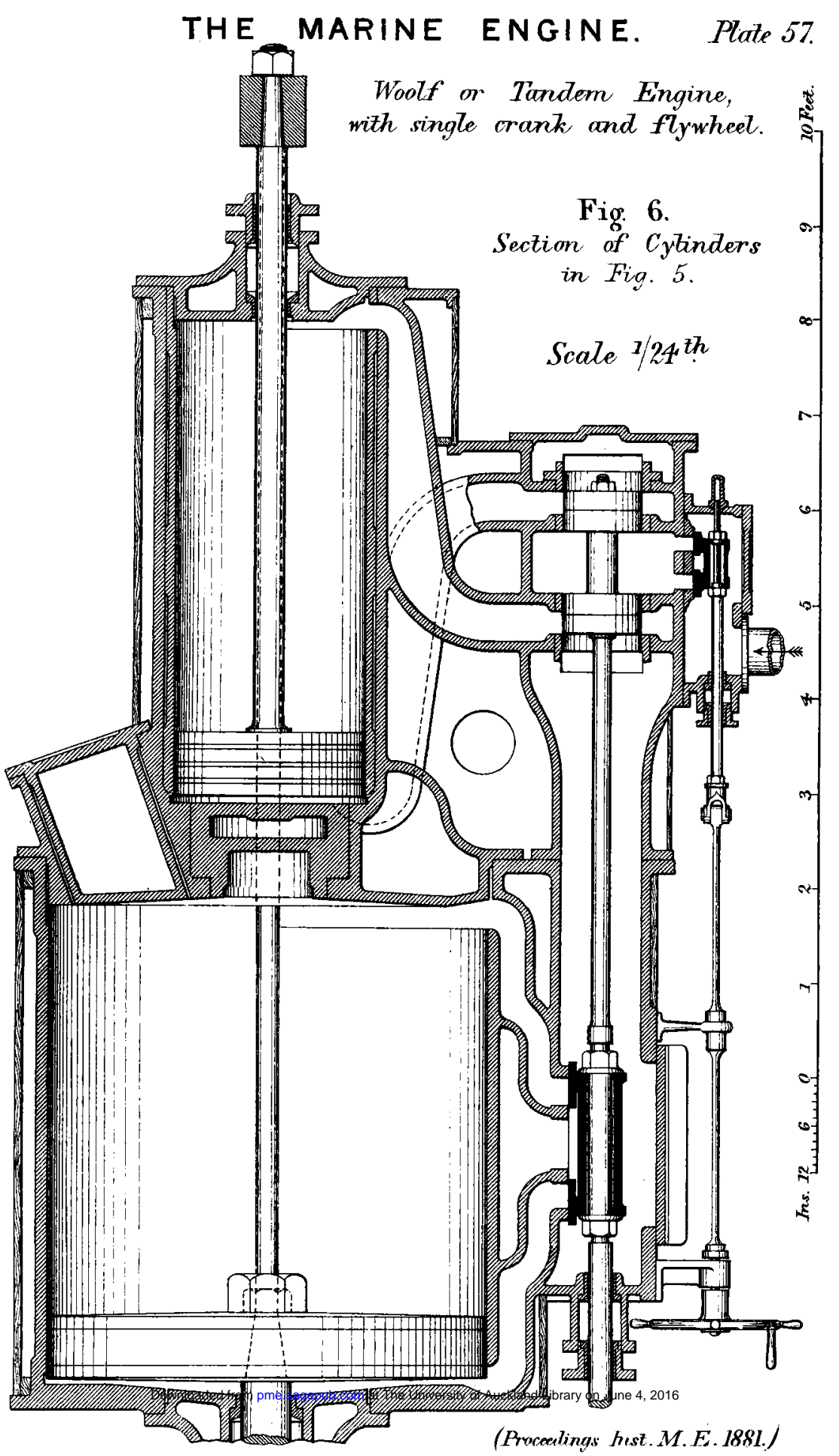


THE MARINE ENGINE. Plate $\delta \delta$.

Fig. 7. Double Woolf or Double Tandem Engine, working two cranks at right angles.

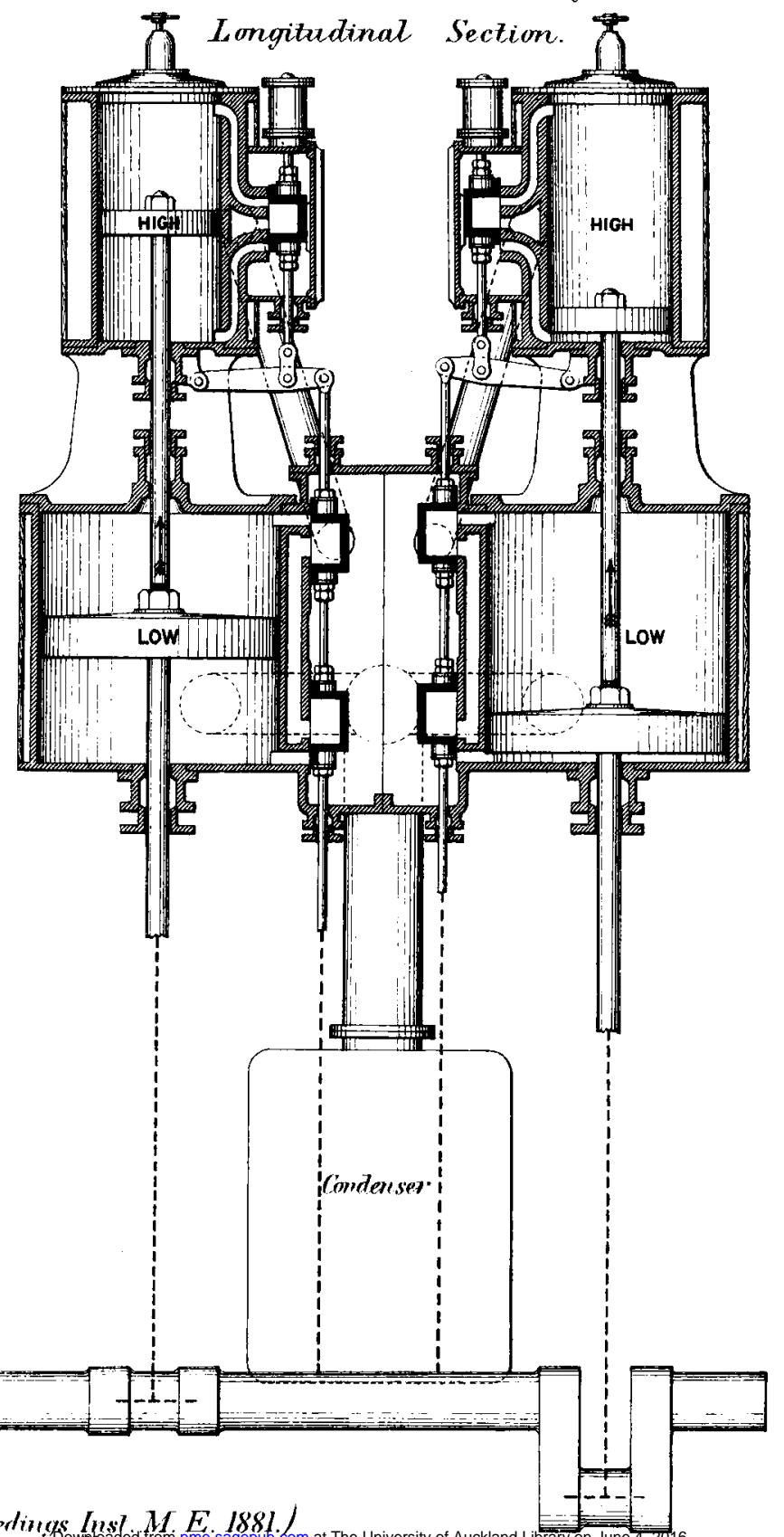

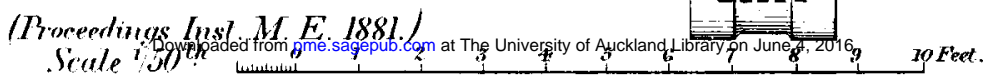


THE MARINE ENGINE.

Plate 59

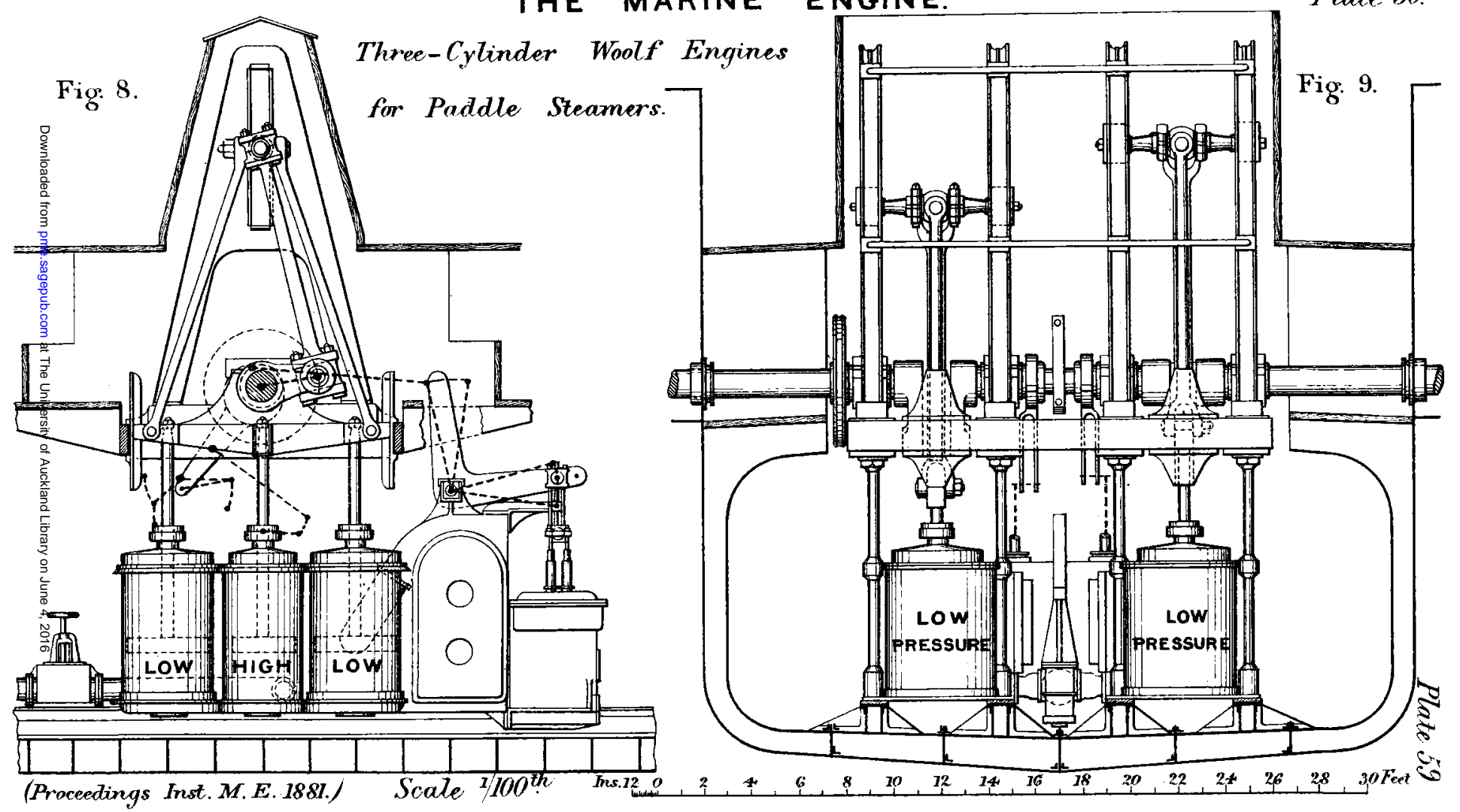




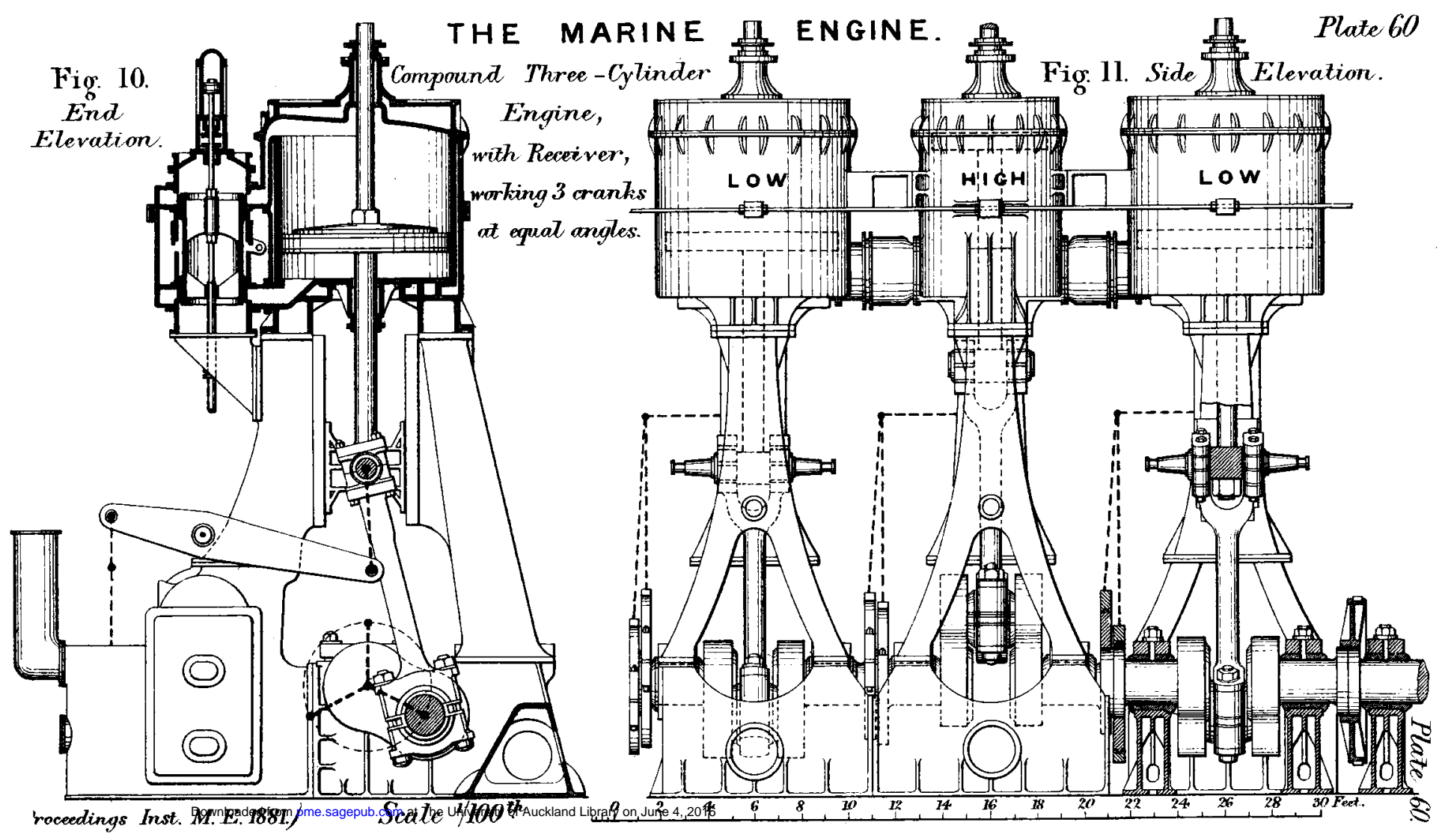


THE MARINE ENGINE.

Plate 61.

Single-ended Marine Boiler

Fig. 12. Back Elevation.

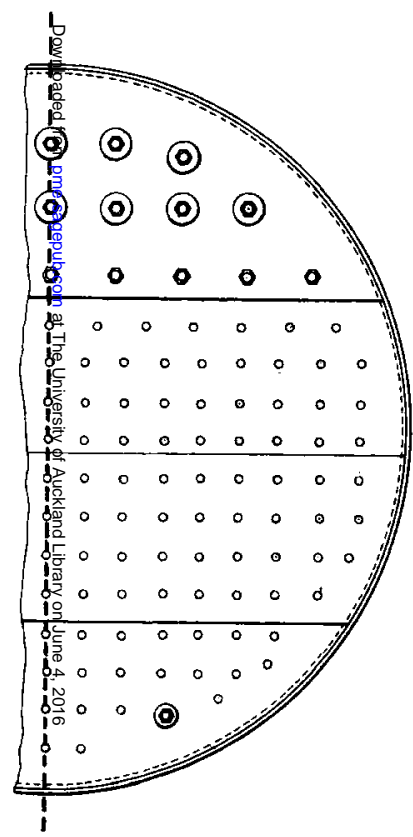

(Procectings Inst. M.E. 1881.)
Fig. 13. Longitudinal Section.

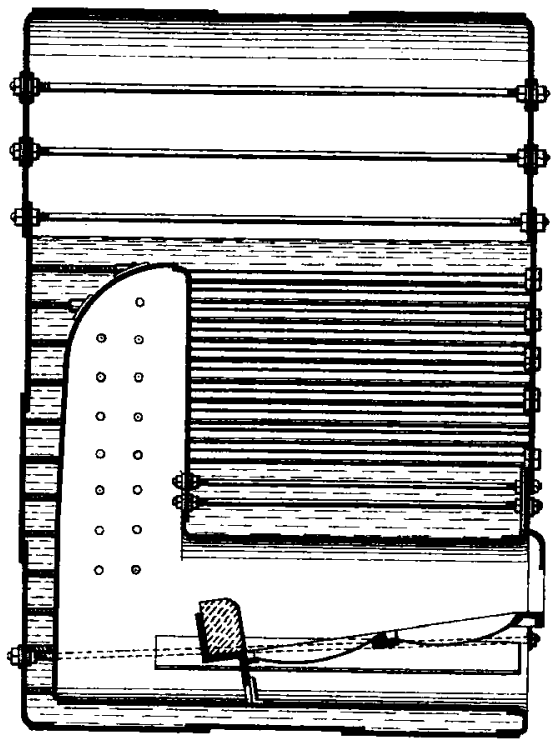

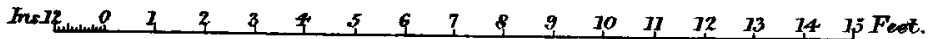

Scale $1 / 60^{\text {th }}$

Fig. 14. Front Elevation and Transverse Section.

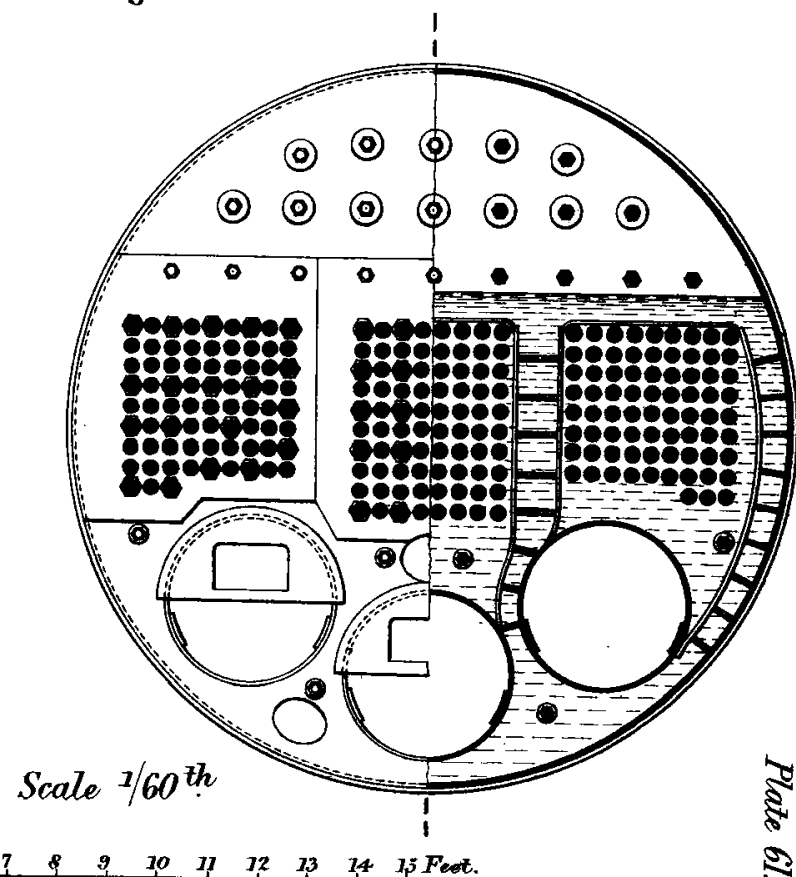


THE MARINE ENGINE.

Plaze 62.

Double-ended Marine Boiler.

Fig. 15.

Find Elevation and Section at $\mathbf{X X}$.

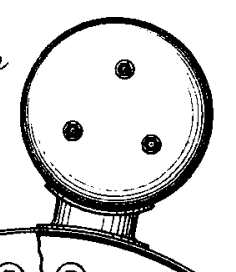

(2) (C) $(0)$

(2) (-) (ㅇ) $(-0)$

- (2) $620=0$

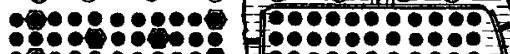
  :86:8:-8: 政

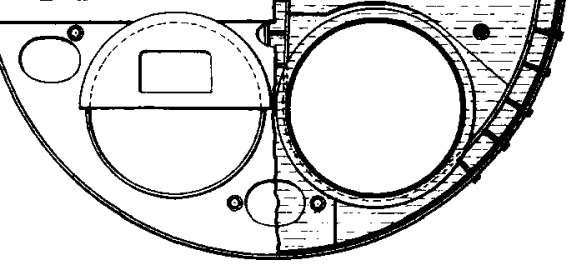

Fig. 16. Longitudinal Section.

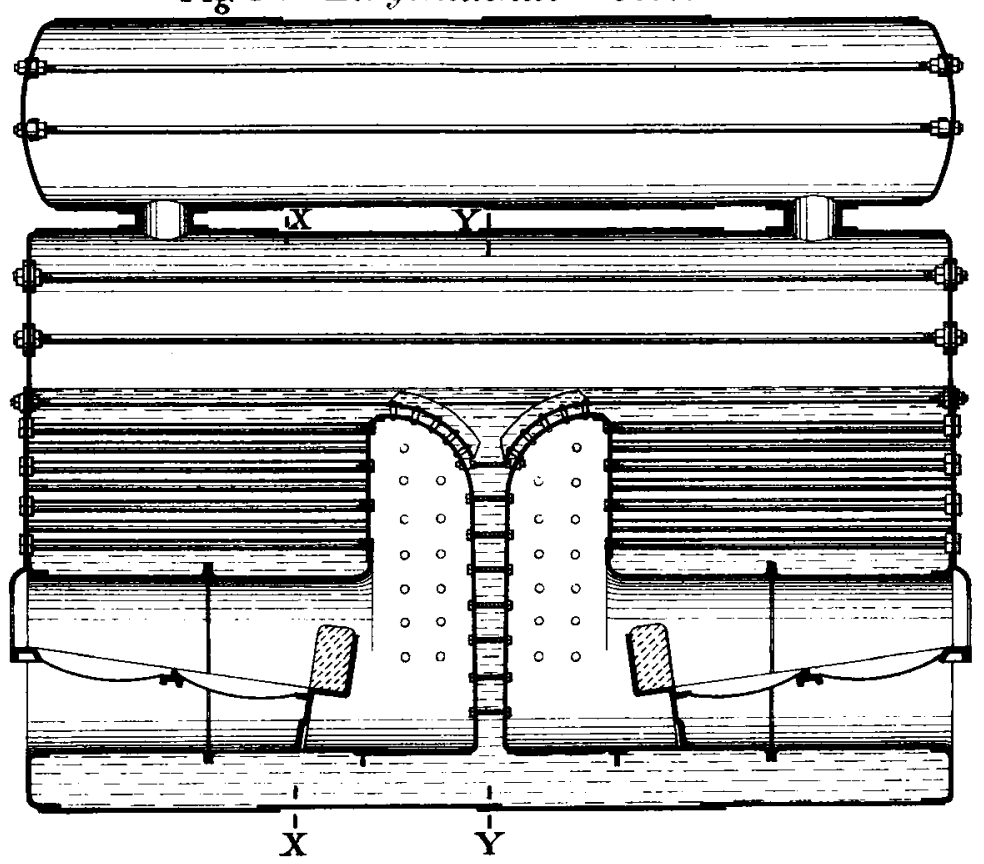

Fig. 17.

Transverse

Section at YY.

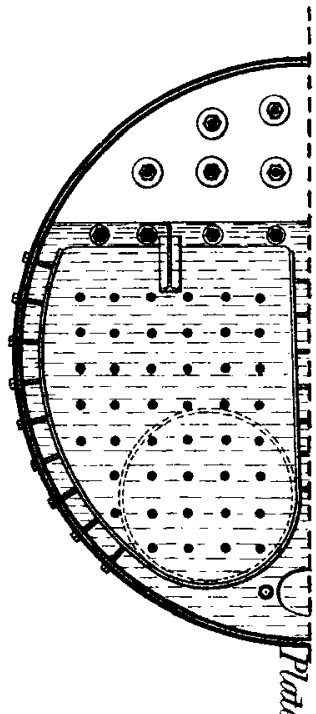

1742920 Fect. ? 
THE MARINE ENGINE.

Double-ended Marine Boiler with single flame-box.

Fig 18. End Elevation and Section at XX.

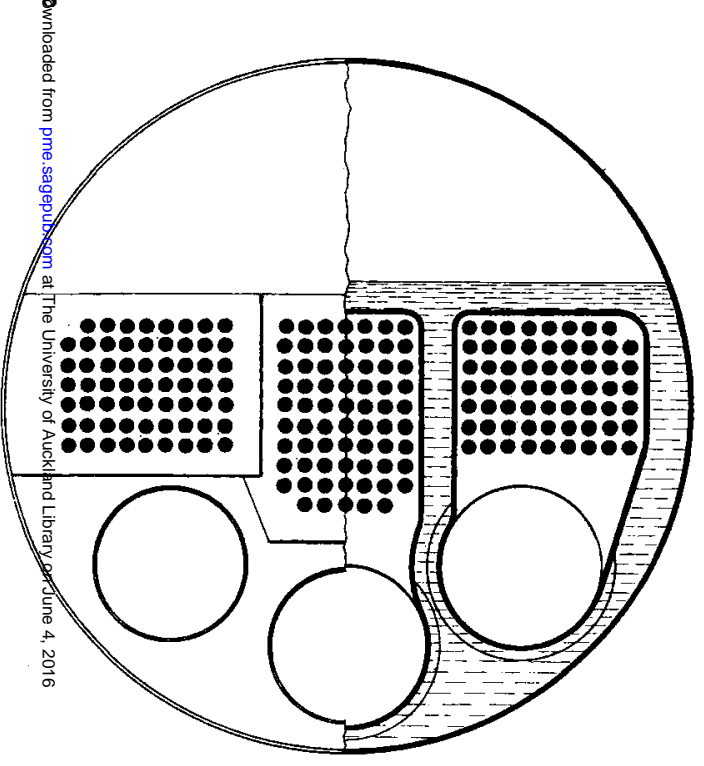

Scate $1 / 60^{\text {th }}$
Fig. 19. Longizadinal Section.

ix
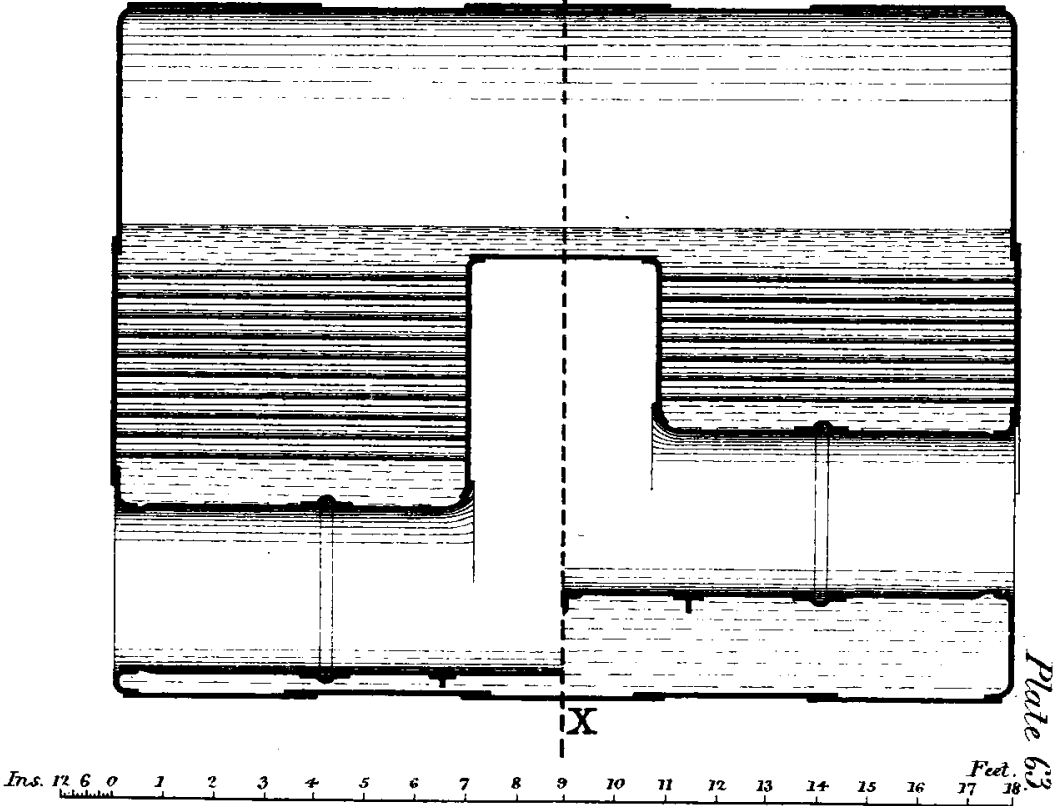


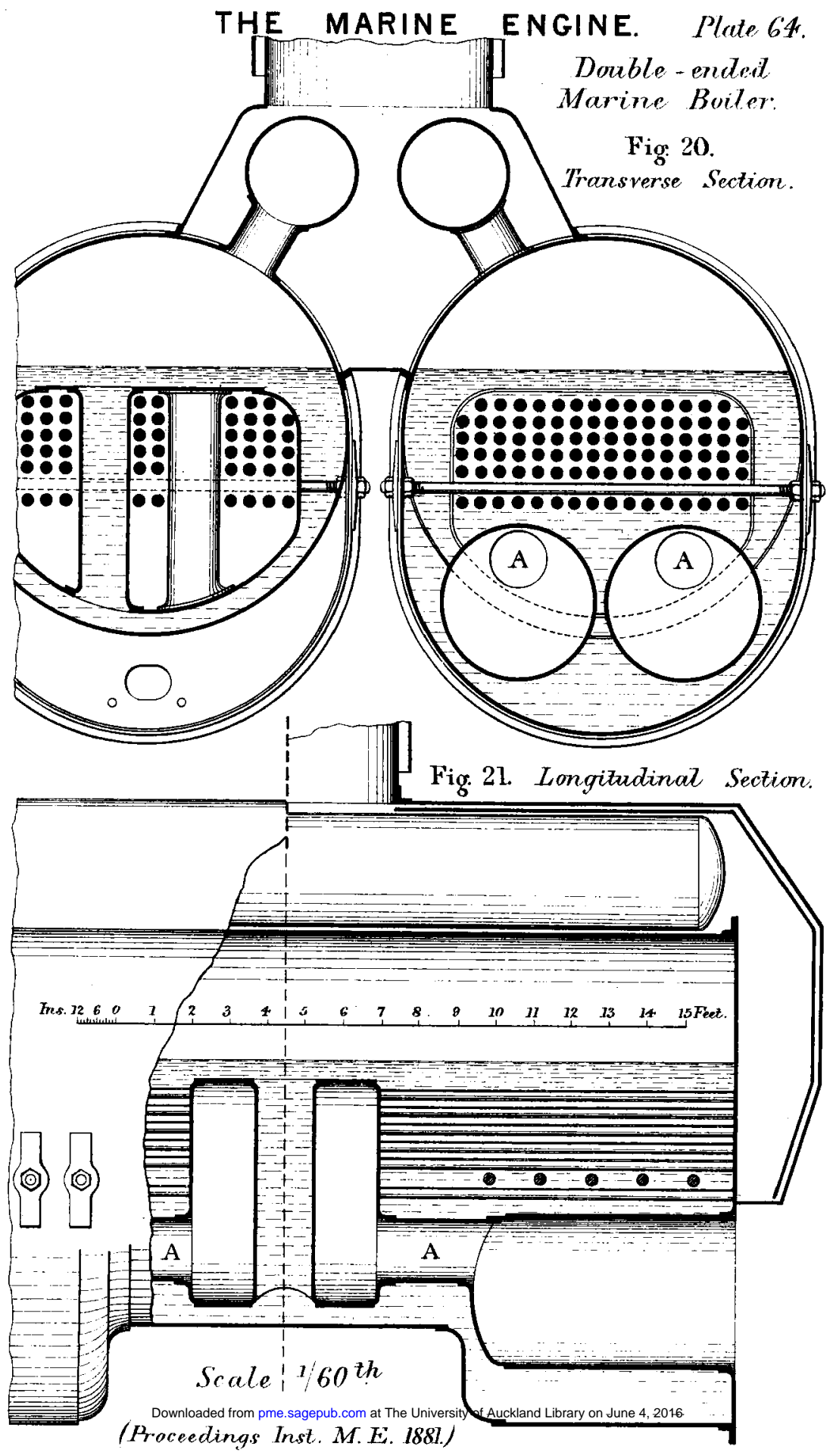


THE M AR I N E

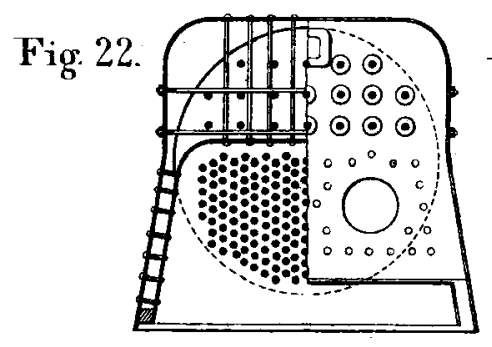

Transverse Sections.
Locomotive - type

Marine Boiler.

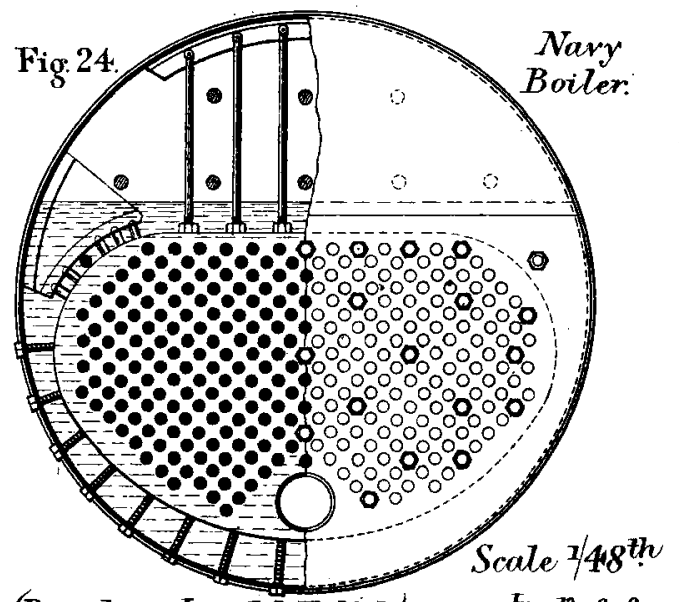

Srale ${ }^{1} / 48^{\text {th }}$

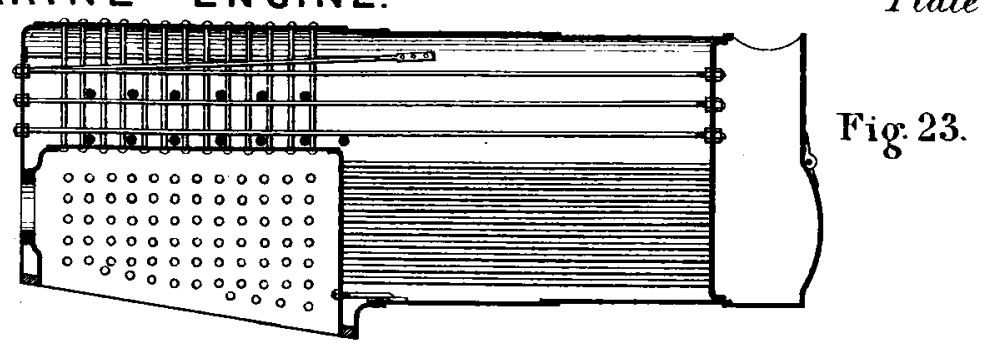

Longitudinal Sections.

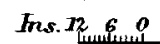

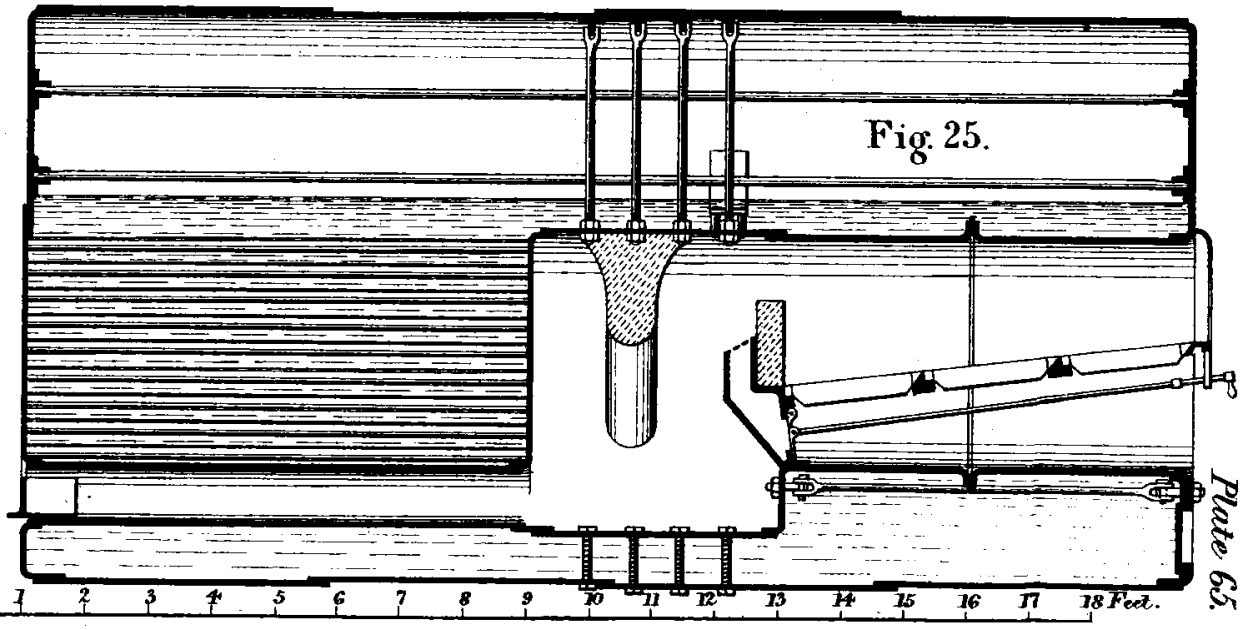


THE MARINE ENGINE.

Plate 66.

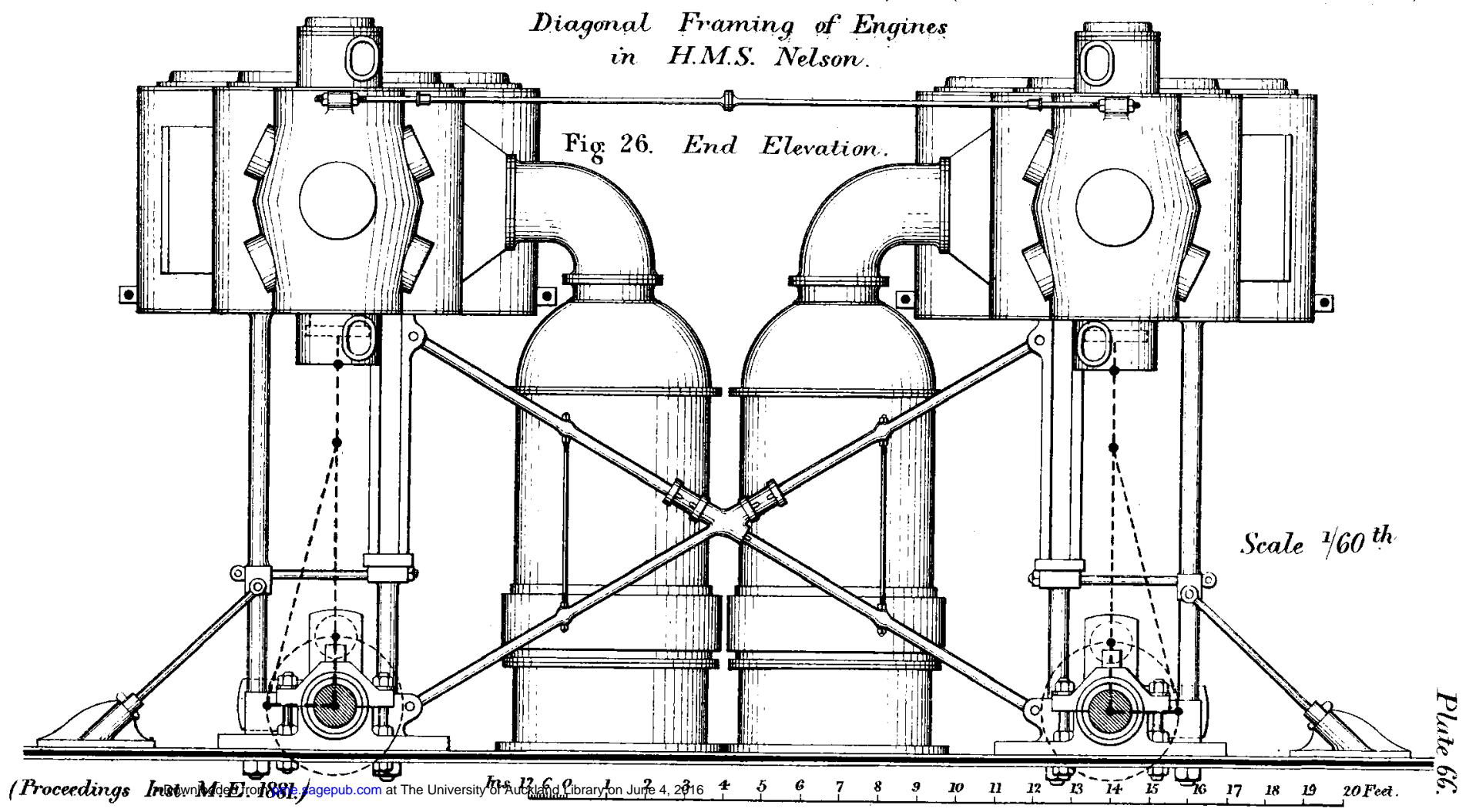




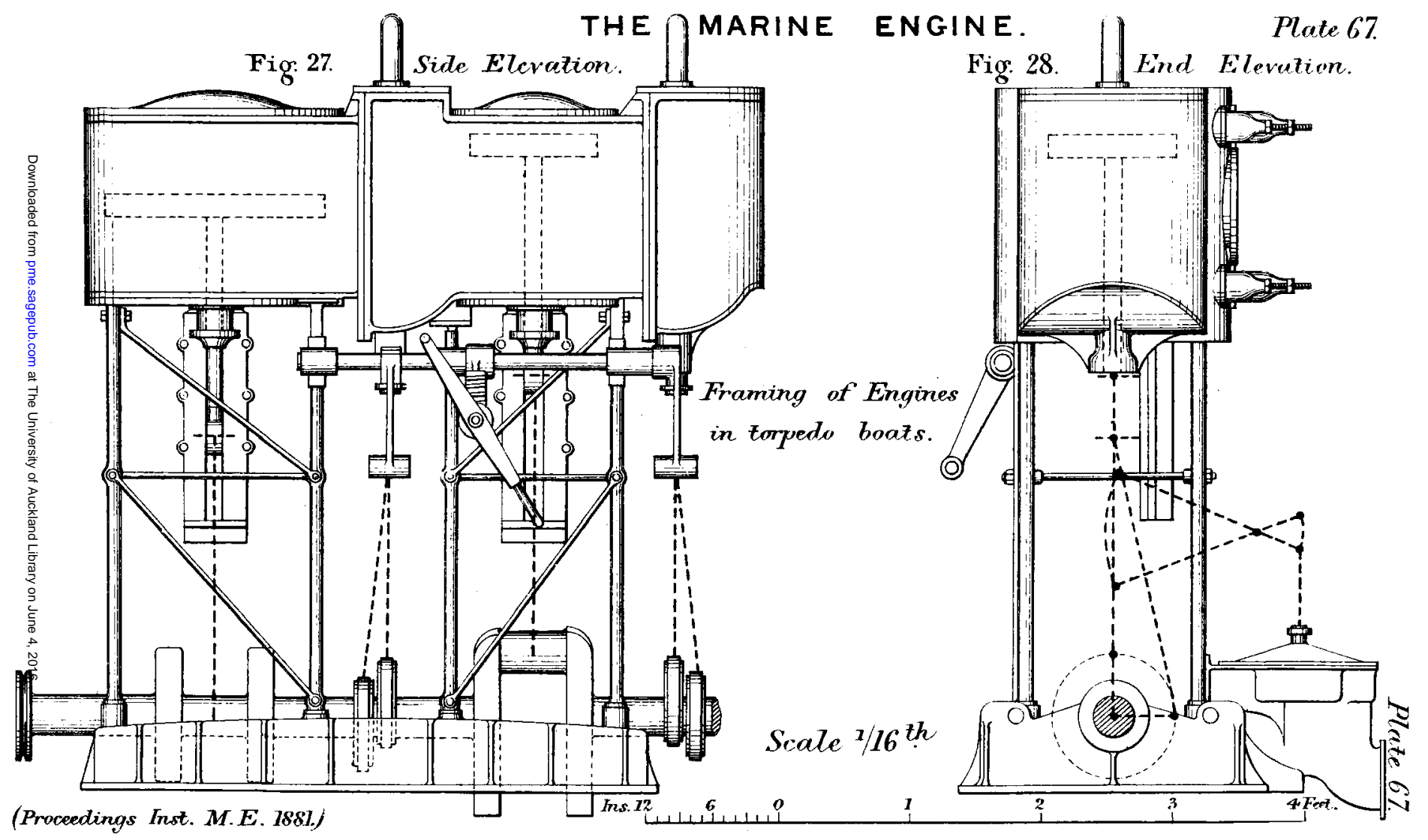




\section{THE MARINE ENGINE. Plate 68.}

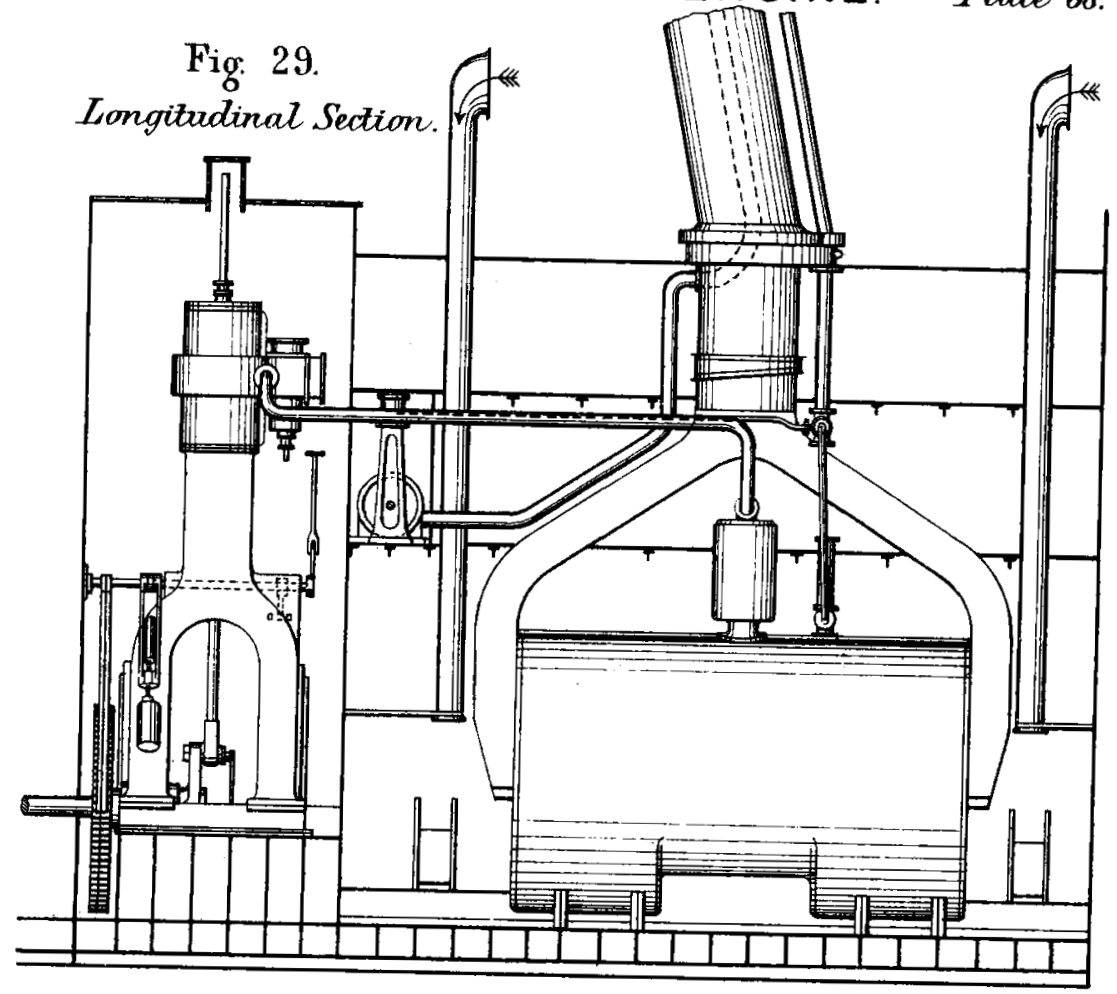

Holt's Single Engine working overhung Crank.

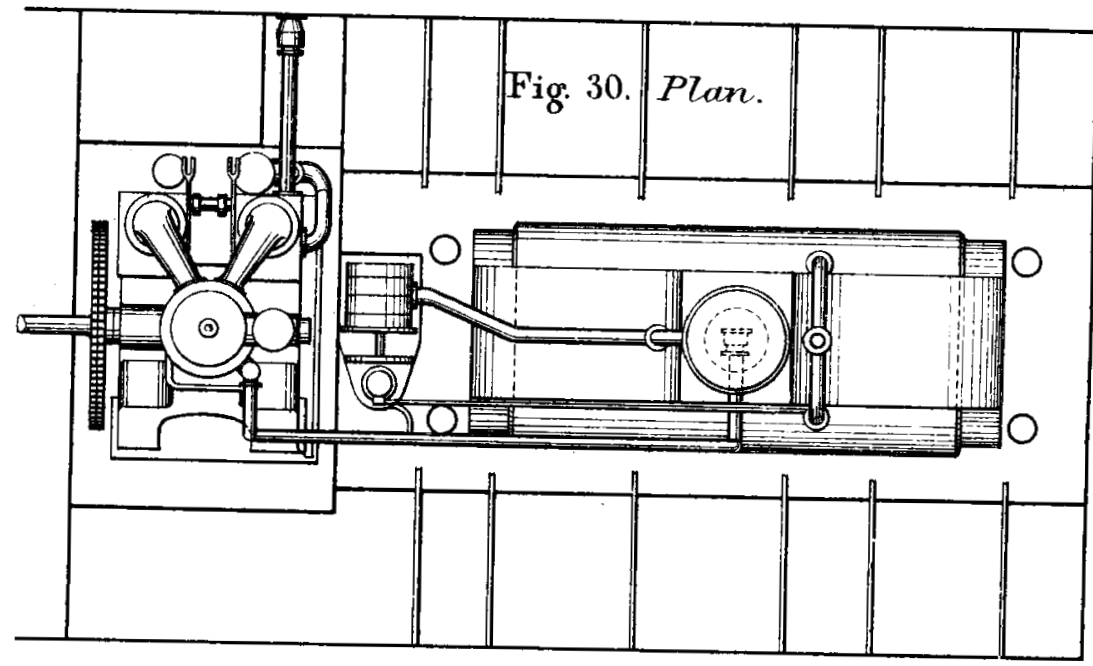




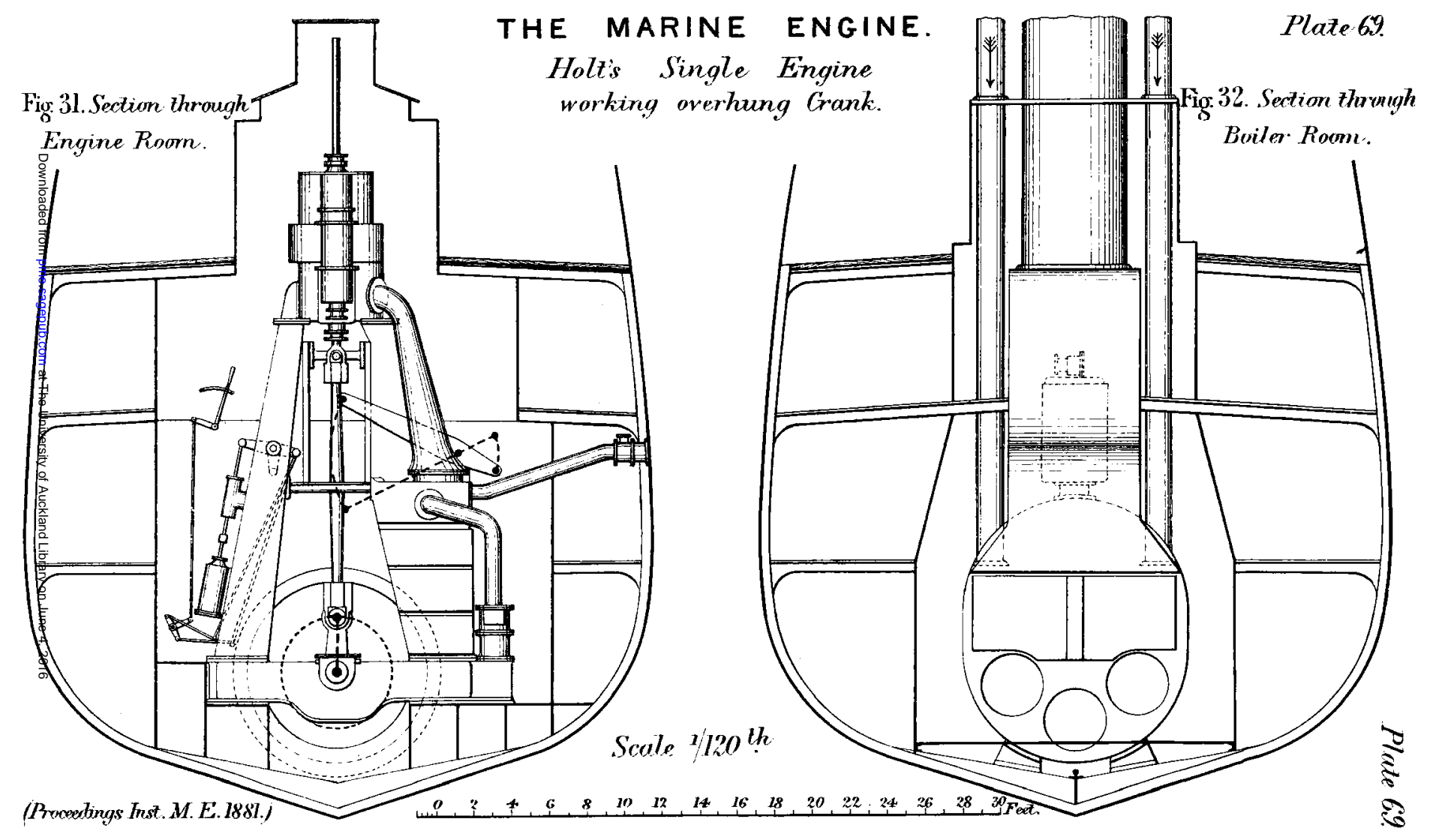


THE MARINE ENGINE.

Thinning of Corners of Steel Boiler Plates in longitudinal lup-joints.

Fig: 35. Transverse Section.

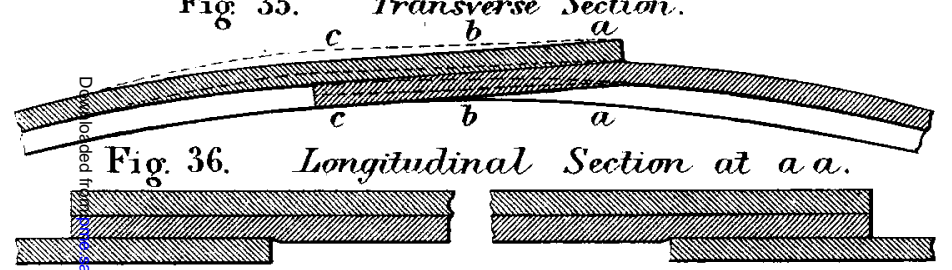

Fig: 37. Longitudinul Section at $b b$.

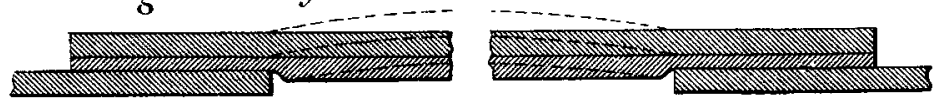

Fig.38. Longitudinal Section at cc.

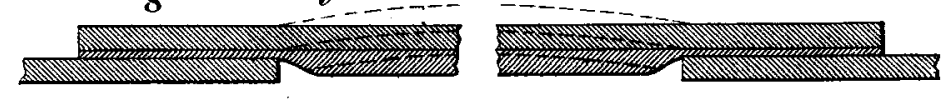

Döglted lines in Figs. 35, 37, 38, indicate straining of plates at joint when not set to proper aurve beforehand.

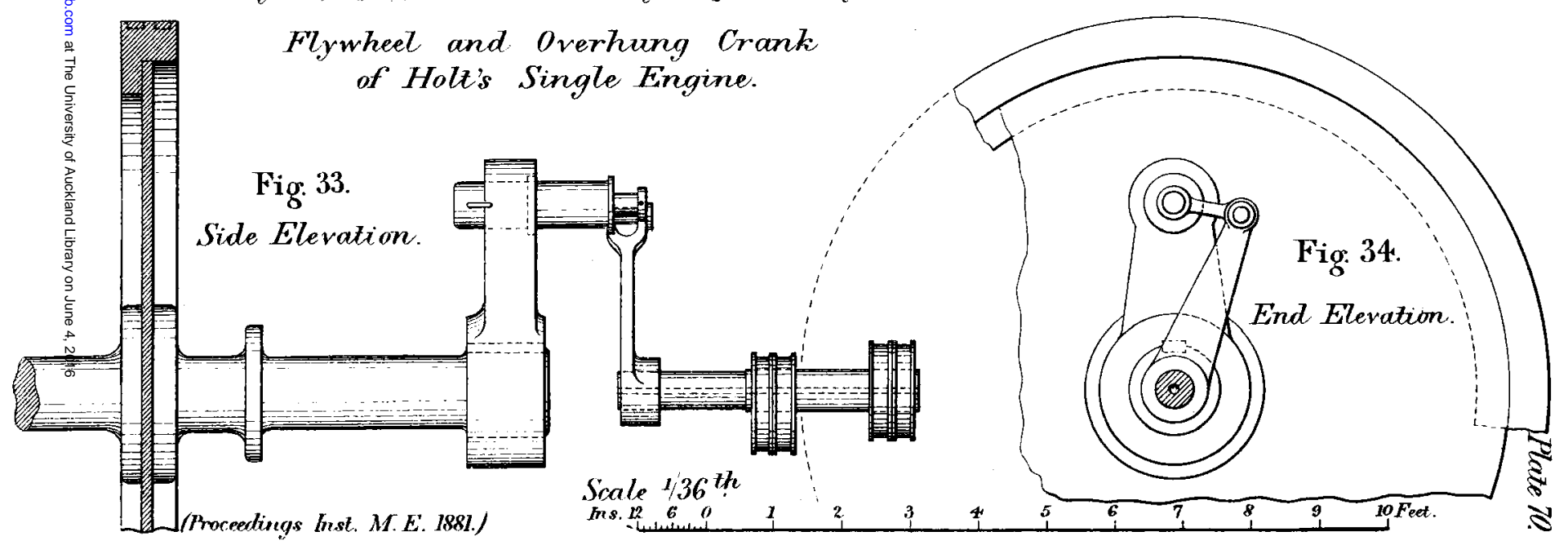


THE MARINE ENGINE.

Plate 71.

Fig. 39.

Transverse

Section.

(O) Locomotive and

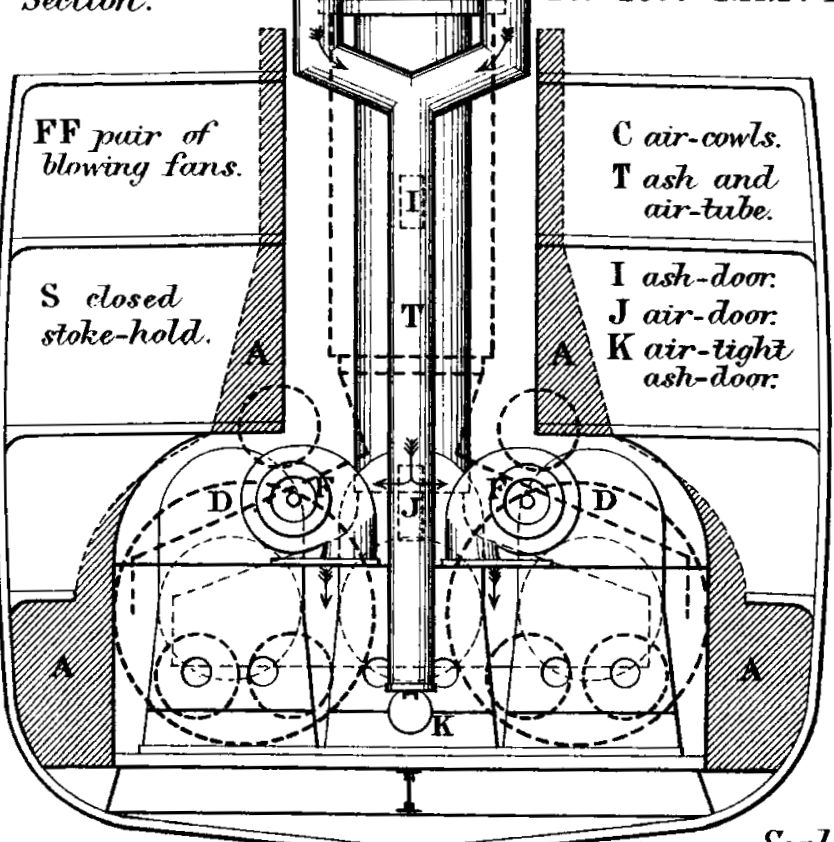

Scale ${ }^{1 / 130^{\text {th }}}$

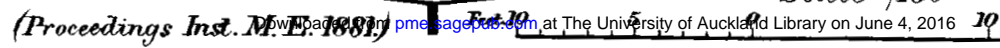

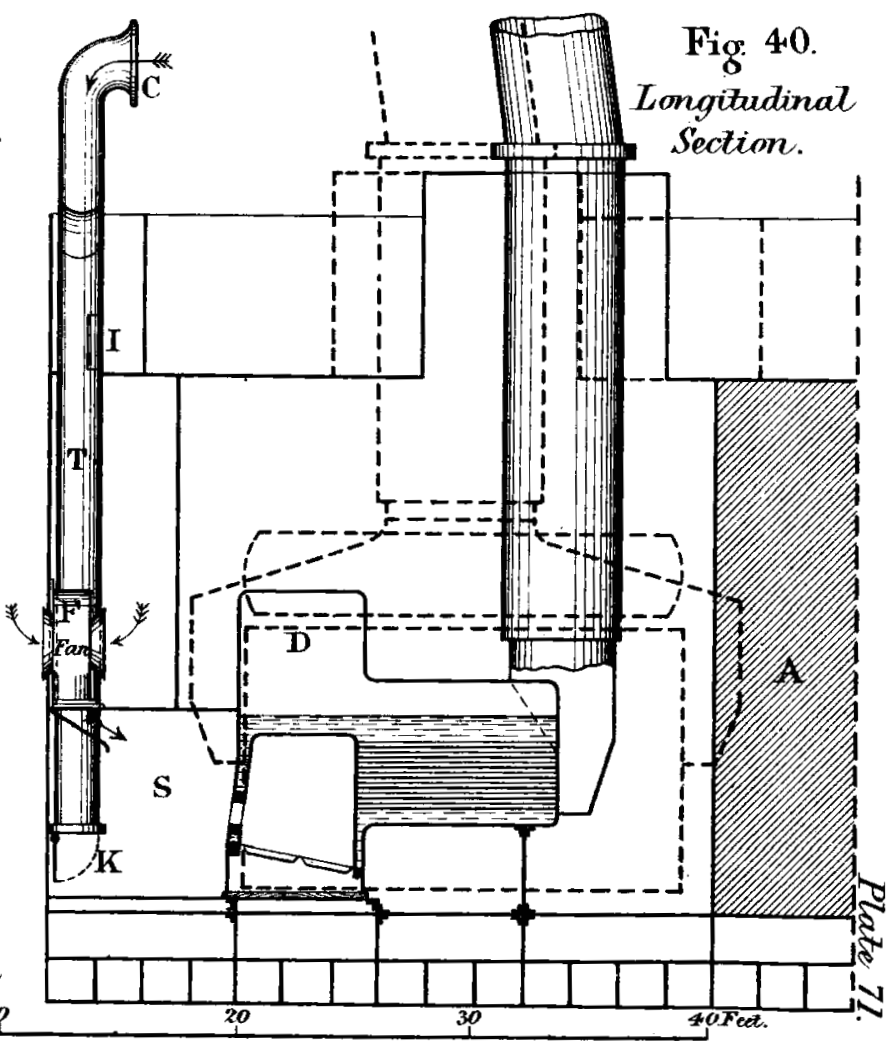

